\title{
Mission Diagnostic Protocol, Version 1.0: A Risk-Based Approach for Assessing the Potential for Success
}

Christopher Alberts Audrey Dorofee

Lisa Marino

March 2008

TECHNICAL REPORT

CMU/SEI-2008-TR-005

ESC-TR-2008-005

Mission Success in Complex Environments

Unlimited distribution subject to the copyright. 
This report was prepared for the

SEI Administrative Agent

ESC/XPK

5 Eglin Street

Hanscom AFB, MA 01731-2100

The ideas and findings in this report should not be construed as an official DoD position. It is published in the interest of scientific and technical information exchange.

This work is sponsored by the U.S. Department of Defense. The Software Engineering Institute is a federally funded research and development center sponsored by the U.S. Department of Defense.

Copyright 2008 Carnegie Mellon University.

\section{NO WARRANTY}

THIS CARNEGIE MELLON UNIVERSITY AND SOFTWARE ENGINEERING INSTITUTE MATERIAL IS FURNISHED ON AN "AS-IS" BASIS. CARNEGIE MELLON UNIVERSITY MAKES NO WARRANTIES OF ANY KIND, EITHER EXPRESSED OR IMPLIED, AS TO ANY MATTER INCLUDING, BUT NOT LIMITED TO, WARRANTY OF FITNESS FOR PURPOSE OR MERCHANTABILITY, EXCLUSIVITY, OR RESULTS OBTAINED FROM USE OF THE MATERIAL. CARNEGIE MELLON UNIVERSITY DOES NOT MAKE ANY WARRANTY OF ANY KIND WITH RESPECT TO FREEDOM FROM PATENT, TRADEMARK, OR COPYRIGHT INFRINGEMENT.

Use of any trademarks in this report is not intended in any way to infringe on the rights of the trademark holder.

Internal use. Permission to reproduce this document and to prepare derivative works from this document for internal use is granted, provided the copyright and "No Warranty" statements are included with all reproductions and derivative works.

External use. Requests for permission to reproduce this document or prepare derivative works of this document for external and commercial use should be addressed to the SEI Licensing Agent.

This work was created in the performance of Federal Government Contract Number FA8721-05-C-0003 with Carnegie Mellon University for the operation of the Software Engineering Institute, a federally funded research and development center. The Government of the United States has a royalty-free government-purpose license to use, duplicate, or disclose the work, in whole or in part and in any manner, and to have or permit others to do so, for government purposes pursuant to the copyright license under the clause at 252.227-7013.

For information about purchasing paper copies of SEI reports, please visit the publications portion of our Web site (http://www.sei.cmu.edu/publications/pubweb.html). 


\section{Table of Contents}

$\begin{array}{lc}\text { Acknowledgements } & \text { ix }\end{array}$

$\begin{array}{lc}\text { Abstract } & \mathbf{x i}\end{array}$

$\begin{array}{llr}1 & \text { Introduction } & 1\end{array}$

2 MOSAIC $\quad 3$

$\begin{array}{lll}2.1 & \text { Missions and Their Objectives } & 7\end{array}$

2.2 Managing for Success using MOSAIC 10

2.3 Analyzing Key Drivers of Success 12

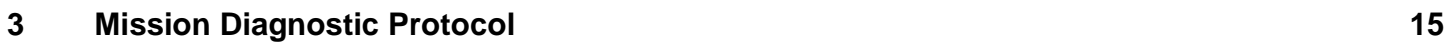

$\begin{array}{lll}3.1 & \text { Protocol Structure } & 17\end{array}$

3.2 Prepare for the Assessment (Phase 1) 18

3.3 Conduct the Assessment (Phase 2) 22

3.3.1 Gather Data from People (Activity A1) 26

3.3.2 Generate Data from Documentation (Activity A2) 30

3.3.3 Evaluate Drivers (Activity A3) 33

3.3.4 Apply Analysis Algorithm (Activity A4) 37

3.3.5 Establish Success Profile (Activity A5) 44

3.3.6 Determine Next Steps (Activity A6) 49

3.4 Complete Post-Assessment Activities (Phase 3) 52

$4 \quad$ Summary and Further Work $\quad 55$

$\begin{array}{ll}\text { Appendix A: Risk Management Concepts } & 58\end{array}$

$\begin{array}{ll}\text { Appendix B: Protocol Structure and Nomenclature } & 65\end{array}$

$\begin{array}{lr}\text { References } & 68\end{array}$ 
ii | CMU/SEI-2008-TR-005 


\section{List of Figures}

Figure 1: A Method Consistent with Protocol A 6

Figure 2: $\quad$ A Second Method Consistent with Protocol A 6

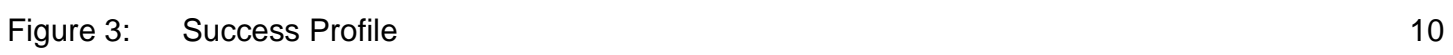

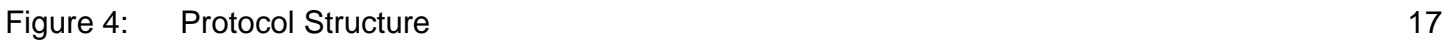

Figure 5: Dataflow for MDP Phase 1 18

Figure 6: Dataflow for MDP Phase 2

Figure 7: Detailed Dataflow for MDP Phase 2 25

Figure 8: Inputs and Outputs for Activity A1 26

Figure 9: Inputs and Outputs for Activity A2 30

Figure 10: Inputs and Outputs for Activity A3 33

Figure 11: Inputs and Outputs for Activity A4 37

Figure 12: Inputs and Outputs for Activity A5 44

Figure 13: Inputs and Outputs for Activity A6 49

Figure 14: Dataflow for MDP Phase $3 \quad 52$

Figure 16: Speculative and Hazard Risks 59

$\begin{array}{ll}\text { Figure 17: } & \text { Common Elements of Risk }\end{array}$

Figure 18: Cause and Effect Risk Statement 64

Figure 19: $\quad$ Protocol Data Types 66 
iv | CMU/SEI-2008-TR-005 


\section{List of Tables}

Table 1: Information Types for all Assessment Phases

Table 2: Information Types for each Phase 2 Activity

Table 3: Dataflow Prefixes

Table 4: Dataflow Identifier Examples 
vi | CMU/SEI-2008-TR-005 


\section{List of Examples}

$\begin{array}{lll}\text { Example 1: } & \text { Set of Drivers } & 28\end{array}$

Example 2: Data from One Person for One Driver $\quad 29$

Example 3: $\quad$ Driver Analysis 32

Example 4: $\quad$ Driver and Range of Values $\quad 34$

Example 5: $\quad$ Criteria for Driver Values $\quad 35$

Example 6: Evaluated Driver 36

$\begin{array}{lll}\text { Example 7: } & \text { Driver Values and Scores } & 36\end{array}$

Example 8: $\quad$ Evaluated Driver Set 39

$\begin{array}{ll}\text { Example 9: } & \text { Success Criteria }\end{array}$

$\begin{array}{lll}\text { Example 10: } & \text { Aggregate Scoring } & 41\end{array}$

Example 11: Weighted Aggregate Scoring $\quad 41$

Example 12: Mean Scoring $\quad 42$

Example 13: Median Scoring 42

$\begin{array}{ll}\text { Example 14: } & \text { Success Criteria }\end{array}$

$\begin{array}{lll}\text { Example 15: } & \text { Success Profile } & 48\end{array}$

Example 16: Next Steps $\quad 51$ 
viii | CMU/SEI-2008-TR-005 


\section{Acknowledgements}

The authors wish to acknowledge the contributions of the following people: Georgia Killcrece, Robin Ruefle, and Mark Zajicek from the CSIRT ${ }^{1}$ Development Team in the SEI Networked Systems Survivability Program for their collaboration in piloting MOSAIC assessments in the incident response domain; and Julia Allen, Eileen Forrester, Georgia Killcrece, and Jeannine Siviy for their reviews of this technical report.

Computer Security Incident Response Team 
X | CMU/SEI-2008-TR-005 


\section{Abstract}

SEI Mission-Oriented Success Analysis and Improvement Criteria (MOSAIC) is a management approach for establishing and maintaining confidence that objectives will be achieved successfully. It comprises a suite of risk-based methods for assessing and managing complex projects and processes. The Mission Diagnostic Protocol (MDP) is one of the assessments included in MOSAIC. MDP provides a time-efficient means of analyzing the potential for success in complex and uncertain environments and can be applied across the life cycle and throughout the supply chain. It produces a broad overview of the current state of risk and opportunity for a project or process. With MDP, a set of key drivers is evaluated to establish current conditions and circumstances that can affect performance. Then, a simple algorithm is used to estimate the likelihood of achieving the objectives being pursued. An MDP assessment is straightforward to conduct, and it can be self-applied by people who are responsible for overseeing projects and processes. The purpose of this document is to describe the core set of activities and outputs that defines MDP. 
xii | CMU/SEI-2008-TR-005 


\section{Introduction}

\author{
MISSION DIAGNOSTIC \\ PROTOCOL
}

PURPOSE OF THIS DOCUMENT
SEI Mission-Oriented Success Analysis and Improvement Criteria (MOSAIC) is a management approach for establishing and maintaining confidence that objectives will be achieved successfully. It comprises a suite of risk-based methods for assessing and managing complex projects and processes. The Mission Diagnostic Protocol (MDP) is one of the assessments included in MOSAIC.

MDP is a risk-based assessment for evaluating current conditions and determining whether a project or process is on track for success. MDP is a time-efficient means of analyzing the potential for success in complex and uncertain environments and can be applied across the lifecycle and throughout the supply chain. An MDP assessment is straightforward to conduct, and it can be self-applied by people who are responsible for overseeing projects and processes.

An MDP assessment provides a broad overview of the current state of risk and opportunity for a project or process. It can be viewed as a first-pass screening to diagnose any unusual circumstances that might affect the potential for success. More detailed, follow-on evaluations might be required when the potential for success is judged to be unacceptable.

The purpose of this document is to define the core set of activities and outputs that defines MDP and present the basic approach, or framework, for conducting an MDP assessment. However, this document does not provide step-by-step procedures for performing an MDP assessment. Guidebook(s) focusing on how to conduct an MDP assessment and domain-specific methods consistent with MDP will be published in the future.

The primary audience for this technical report is people who have experience assessing and managing risk in development and operational settings. This includes people who oversee complex projects and processes. People who have experience with or are interested in the following topics might also find this document useful:

- time- and resource-efficient methods for assessing and managing risk

- general project or program management

- success-driven management of projects or processes 
STRUCTURE OF THIS DOCUMENT
This technical report is divided into the following parts:

- Section 1: Introduction-provides a brief overview of MDP and defines the audience for this document

- Section 2: MOSAIC — presents background information about MOSAIC and its assessment methods

- Section 3: Mission Diagnostic Protocol—describes the driverbased approach of MDP, including an overview of each activity

- Section 4: Summary and Future Work-presents a brief synopsis of research and development activities related to MOSAIC and MDP

- Appendix A: Risk Management Concepts - provides a basic overview of risk management concepts and philosophy

- Appendix B: Protocol Structure and Nomenclature-describes the standard structure and naming conventions for the MDP data flows 


\section{MOSAIC}

INTRODUCTION

A New Approach for A Complex Problem SPACE
This section provides background information about the body of research underlying MOSAIC and MDP. It also provides significant concepts and terminology needed to understand MDP, specifically:

- basic structure of MOSAIC assessment methods

- focus on managing key objectives

- success-oriented philosophy of MOSAIC

- driver-based analysis approach

Today's business, project, and operational environments are becoming increasingly complex. People often struggle to make sense of this complexity, which places many critical projects and processes at risk of failing. MOSAIC is a management approach that establishes and maintains confidence that objectives will be achieved successfully. It comprises a suite of risk-based methods for assessing and managing complex projects and processes [Alberts 2007].

MOSAIC is a highly flexible approach that can be applied across the life cycle and used to manage projects and processes that cross organizational boundaries. It is designed to help people analyze tradeoffs and make better decisions in situations that have a high degree of uncertainty. MDP is one of the assessments included in MOSAIC.

To date, MOSAIC research and development activities have primarily focused on assessing the success potential of projects and processes. As a result, this document examines how MDP is used in the context of projects and processes. As MDP is used in other contexts (e.g., to assess technology), additional guidance will be provided. 
Projects

Processes

\section{OUTCOME}

MANAGEMENT
In MOSAIC, a project is defined as a set of activities that produces a unique product for a customer or delivers a service that is tailored for a customer's needs. A project is often executed only once. For example, when an organization develops a software-intensive system for a specific customer, its management charters a project to develop that system. The project begins with the initial concept for the system and ends when the system is satisfactorily delivered to the customer. Projects can range from small software development projects with 5 or 10 people to a large Department of Defense (DoD) systems development program that includes multiple government and contractor organizations.

In contrast to a project, a process is a set of activities that is typically executed more than once. Two types of processes are considered in MOSAIC: business and operational processes. In this document, a process that provides a core business function is called a business process. For a healthcare organization, the patient-care workflow is considered to be a core business process because it directly supports the mission of the organization (i.e., to provide healthcare services to patients). In contrast, an operational process indirectly supports the mission of the organization. It is not part of the organization's revenue-producing processes. An information technology (IT) process for configuring and maintaining an organization's computing infrastructure is an example of an operational process. The term process as used in this document refers to both operational and business processes.

MOSAIC methods help decision makers establish and maintain a reasonable degree of confidence that projects and processes will successfully achieve their defined objectives. The overarching goal of this approach is to ensure that the eventual outcome, or result, satisfactorily achieves the objectives being pursued. The focus on managing outcomes enables decision makers to balance potential gain being pursued (i.e., opportunity) against the potential losses that can occur (i.e., risk), which then enables decision makers to define a path toward achieving success. 
Assessment

Protocols,

ACTIVITIES, AND

TECHNIQUES

Protocol Flexibility While you can use a single technique to achieve the goals of a given protocol activity, you might decide to combine several techniques to meet the goals. In this regard, MOSAIC offers considerable flexibility in tailoring an assessment to a particular environment or set of circumstances.

SUPPORTING ARTIFACTS

ASSESSMENT METHODS

Each MOSAIC assessment and management method is based on a specific protocol. As used in this context, a protocol is the basic approach, or framework, for conducting an assessment or management method. It defines the sequence of activities that must be performed but does not indicate how to perform those activities. You can think of a protocol and its associated activities as providing the basic requirements for conducting an assessment.

A technique is a specific practice that can be used when performing a protocol activity. For example, consider the following protocol activity: Gather data from people. Many interviewing and surveying techniques can be used to gather data from people who are knowledgeable about a subject. The objective is to select the technique that is most appropriate for your circumstances. In some cases, an interview might be the best choice, while in other instances a survey that people complete anonymously would be more appropriate. Either way, you get the needed information; you just use different means to collect it.

When you conduct any technique, you will likely use one or more supporting artifacts to gather, analyze, or record data. Worksheets, templates, and tools are all examples of supporting artifacts. Suppose for the protocol activity Gather data from people you decide to conduct an interview with a set of carefully chosen participants. During the interview session, you frame the discussion around a set of key questions. That list of questions, which is essential for conducting an efficient and effective interview, is an example of a supporting artifact.

Protocols (and their associated activities), techniques, and supporting artifacts form the basis for assessment methods in MOSAIC. Figure 1 shows how a method is created by linking techniques and supporting artifacts with a protocol's activities. The collective set of techniques and artifacts used to conduct the protocol (represented by the shaded boxes) constitute a method for that protocol. 
Protocol

\author{
Protocol Activities \\ Techniques \\ Supporting Artifacts
}

Multiple Methods CONSISTENT WITH A PROTOCOL
With MOSAIC, multiple methods can be consistent with a given protocol, as illustrated in Figure 2. A common protocol forms the basis for the methods illustrated in Figure 1 and Figure 2. However, the two methods incorporate different techniques and artifacts. The two methods accomplish the same objectives as defined by the common protocol they follow, but each incorporates a unique combination of techniques and artifacts.

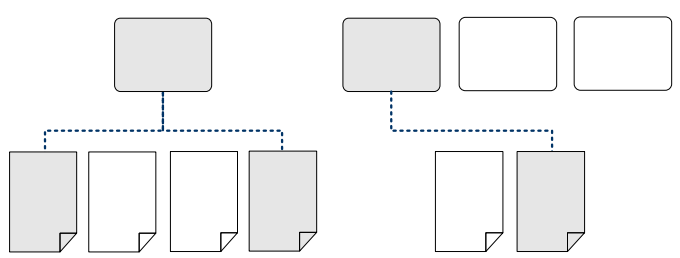

Figure 1: A Method Consistent with Protocol A

Protocol Activities

Activity A.1

Activity A.2

Activity A.3

Techniques
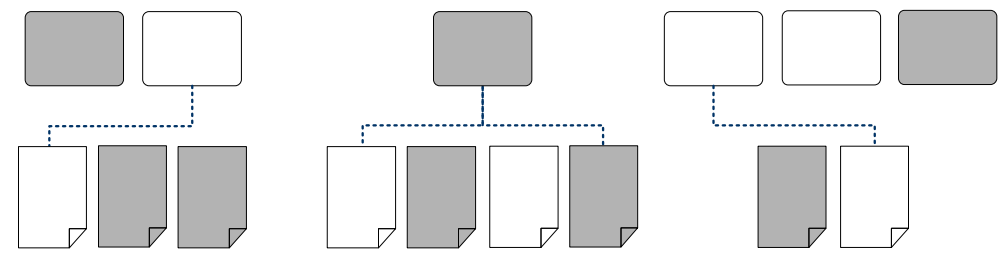

Figure 2: A Second Method Consistent with Protocol A

Broad ApPLICABiLity OF MDP
The protocol defined in this document, MDP, can be applied to many different domains and types of problems. To date, MDP has been applied to both software development projects and operational processes, which illustrates MDP's portability across the life cycle. In general, the flexible design of MOSAIC assessment and management methods allows them to be applied in a variety of domains and environments, across the life cycle, and throughout the supply chain. The main focus when applying MDP in any domain or problem space is to assess the likelihood that key objectives will be achieved successfully. 


\subsection{MISSIONS AND THEIR OBJECTIVES}

What IS A Mission?

NETWORK OF Missions

MOSAIC DEFINITION OF MISSION
The term mission has different meanings, depending on the context in which it is used. ${ }^{2}$ For example, mission is used to describe any of the following:

- the purpose of an organization

- the goals of a specific department or group within a larger organization

- the specific result being pursued when executing a project ${ }^{3}$ or process

- the objectives of each activity in a work process

- the function of each technology (e.g., a software-intensive system) that supports a project or process

A broad network of missions exists within all organizations. Success at the organizational level requires ensuring that all missions within the network are aligned. Ensuring alignment among an organization's missions helps establish confidence that (1) core business missions within the organization will be achieved and (2) the organization's overall mission will also be accomplished.

The network of missions can also extend across multiple organizations. For example, when multiple companies collaborate on a joint venture, such as building and fielding a complex software-intensive system, they pool their resources toward achieving a common mission. Each organization must balance its local objectives against the shared set of objectives defined by the common mission.

Within the context of projects and processes, we define mission as the set of objectives, or desired outcome, of a project or process within one organization or spanning multiple organizations. Put another way, the mission defines what success looks like for a project or process.

The mission of a project or process typically comprises three distinct types of objectives: (1) product or service, (2) cost, and (3) schedule. These three objectives define the tangible, and in many cases, measurable, outcomes being pursued.

\footnotetext{
We assert that mission is a recursive concept.

3 A project, as defined in this document, includes small, independent efforts as well as large scale, multi-organizational, geographically distributed DoD programs.
} 
Product AND Service Objectives

COST AND SCHEDULE OBJECTIVES

Picture OF Success
Product objectives define the nature of the items produced. These objectives are often referred to as technical objectives in the software development domain. For example, if you are developing a softwareintensive system, the product (i.e., technical) objectives define the functional and performance characteristics of the system as well as other desired attributes, like safety or security. Product objectives thus define the parameters of success for the products you build.

Service objectives define the nature of the services provided to the recipients of those services (i.e., customers). If the service you are providing is help-desk support, the service objectives will define the quality of help-desk support provided to constituents (such as the required response time based on the priority of the request). Service objectives define the parameters of success for the services you provide to customers.

In some instances, a mission is defined solely by its product or service objectives. However, in most cases, constraints are also considered in relation to product or service objectives. Managers generally do not have limitless funds at their disposal, nor do they have an infinite amount of time in which to complete work tasks. As a result, cost and schedule objectives must be considered alongside product or service objectives (and in many cases are the key drivers of management's decisions, especially as time goes by and costs accrue).

Product or service, cost, and schedule objectives, when viewed together, typically define the basic mission of a project or process. They specify what will be accomplished, the anticipated costs to complete all activities, and the time frame in which work will be completed. When appropriate, these objectives can be supplemented with other objectives (such as business or financial objectives) to produce a complete picture of success. The mission, or picture of success, defines the desired outcome for a project or process. Once the desired outcome is established, management activities must be geared toward ensuring that results satisfy that outcome. Risk management is an essential part of achieving that success. (Appendix A of this document highlights the foundational concepts of risk management as used in MOSAIC.) 


\section{AN INCOMPLETE \\ Picture Using \\ TRADITIONAL RISK \\ MANAGEMENT}

Organizations typically manage several types of risk using traditional approaches, including project risk, security risk, technology risk, and operational risk. Each type of risk is differentiated by the unique sources, or causes, that produce it. Normally, responsibility for managing different types of risks is assigned to different groups within an organization.

Because each type of risk is normally managed in isolation, it is difficult to establish the overall success potential of a project or process using traditional risk-management approaches. Since different groups in an organization have responsibility for managing different types of risk, each group tends to locally optimize its mitigation efforts. No one is responsible for consolidating disparate risk data. As a result, the overall chances for success are not explicitly determined. In contrast, a MOSAIC assessment is specifically designed to establish the overall success potential of a project or process by analyzing a broad range of success and failure drivers. 


\subsection{MANAGING FOR SUCCESS USING MOSAIC}

SUCCESS-ORIENTED PHILOSOPHY

POTENTIAL FOR SUCCESS

\section{Success Profile}

The MOSAIC management approach requires establishing and maintaining a reasonable degree of confidence that project or process objectives will be achieved successfully. This success-oriented philosophy requires managers to focus their attention on managing the result, or outcome, of a project or process. The goal is to ensure that the eventual outcome fulfills the objectives being pursued.

Traditional risk-management approaches generate a set of risks for a project or process. Each risk in the set is a cause-effect pair that conveys the potential consequence triggered by a single condition or event. In contrast, MOSAIC

- Focuses on the desired outcome (i.e., the objectives being pursued) and

- Examines the range of conditions and potential events that influence the chances of achieving the desired outcome.

The potential for success characterizes the likelihood, or probability, that the desired outcome will be achieved or exceeded. It can be expressed qualitatively in relation to a set of evaluation criteria or quantitatively, depending on the assessment method that is used.

As shown in Figure 3, the success profile depicts the current potential for success in relation to its success threshold, which is the desired, or target, potential for success. The success threshold separates acceptable values of the potential for success from those that are considered to be unacceptable.

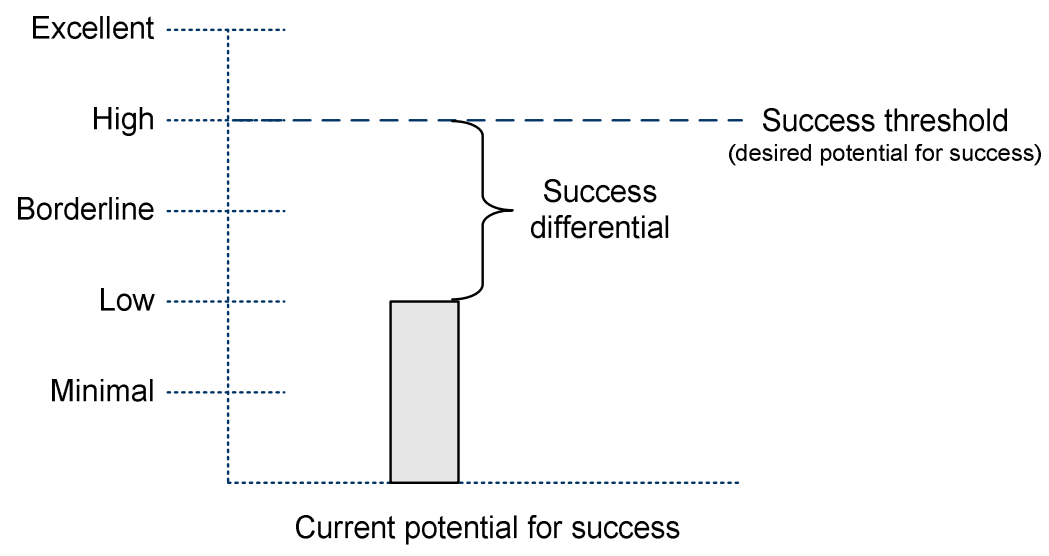

Figure 3: Success Profile 
SUCCESS

DifFERENTIAL

MANAGING THE

POTENTIAL FOR

SUCCESS
As depicted in Figure 3, the success differential is a measure of the current potential for success in relation to the desired value as defined by the success threshold. The success differential illustrates the degree of improvement that will be required to position a project or process for success.

When applying the MOSAIC approach, people (1) assess the current potential for success in relation to its desired value (i.e., its success threshold) and (2) take planned action, when appropriate, to bring the potential for success in alignment with the success threshold.

MOSAIC requires people to track the potential for success over time and take appropriate action as needed to ensure that the potential for success is kept within an acceptable tolerance.

Mission Assurance

Mission assurance is defined as the level of confidence that mission objectives will be achieved successfully. When viewed within the context of a project or a process, mission assurance focuses on establishing and maintaining an appropriate level of confidence in the potential for achieving project or process objectives. MOSAIC is a means of achieving the desired level of mission assurance for projects or processes. 


\subsection{ANALYZING KEY DRIVERS OF SUCCESS}

Purpose of

RESEARCH AND

DEVELOPMENT

WHAT IS A DRIVER?

SUCCESS AND FAILURE DRIVERS
An extensive and time-consuming analysis is normally required when conducting most commonly used risk assessments. An underlying goal of the Software Engineering Institute (SEI) research and development activities related to MDP is to demonstrate that an assessment does not require a significant investment of time to be effective. In this way, people can more readily adopt risk-based approaches that help them weigh the alternatives confronting them and ultimately make better decisions.

The goal of all MOSAIC assessments, including MDP assessments, is to determine the success potential of a project or process. This focus on managing success clearly distinguishes MOSAIC from traditional risk management, in which the goal is to avoid failure. A key aspect of MOSAIC's success-oriented approach is being able to assess a project's or process' overall chances of succeeding. An MDP assessment determines the potential for success by using a simple algorithm to analyze $a$ small set of key outcome drivers.

Drivers are characteristics of a project or process that are essential for achieving its objectives. Each individual driver has a strong influence on the ultimate outcome, or result. The cumulative effects of all drivers can be analyzed to determine whether a project or process has sufficient momentum toward its objectives. Establishing the effects of drivers is crucial when analyzing the potential for success.

In MDP assessments, each driver is, by definition, worded as a success driver. Consider the following example: Task execution is effective and efficient. Here, the implication is that people have sufficient capability to complete their assigned tasks. This is obviously a positive characteristic of a project or process that helps enhance its potential for success, which makes it a success driver.

Further, MDP assessments determine which drivers from a set are guiding a project toward a successful outcome and which are not. When a given driver does not have a positive influence on a project or process, it is acting as a failure driver. Here, the driver is reducing the momentum toward achieving objectives and making an unsuccessful, or failed, outcome more likely. For example, if people do not have sufficient capability to complete their assigned tasks, the success potential of the project or process is adversely affected. 
Each driver is characterized as a yes/no question, where an answer of yes denotes a success driver and an answer of no denotes a failure driver. Examples of driver questions used in an MDP assessment include

- Are project goals realistic and well articulated?

- Are customer requirements and needs well understood?

- Are organizational and political conditions facilitating completion of project activities?

Note: Refer to Example 1: Set of Drivers on page 28.

Since an important aspect of an MDP assessment is time efficiency, you need to keep the number of drivers small to ensure that the assessment can be completed in a reasonable amount of time. Experience has shown that good results are achieved by using between 10 and 15 drivers in an assessment.

TAILORING DRIVERS to The driver set should be tailored for each specific context because it is REFLECT KEY essential that drivers provide meaningful information about a project or Characteristics of SUCCESS process. A generic set of drivers, such as those featured in Example 1: Set of Drivers on page 28, can be used as a starting point for an assessment. However, you need to ensure that the driver set used to assess a project or process accurately reflects the key characteristics that define success for that project or process.

Whenever you tailor drivers for an assessment, you need to make sure that the driver set addresses all key aspects of the project or process being assessed. In general, you should ensure that a set of drivers minimally addresses the following aspects of a project or process:

- the project or process objectives, including technical, funding and schedule objectives

- the product being developed or the service being provided

- planning and preparing to execute a project or process

- execution of tasks and activities

- the operational and business environments

- capacity and capability to manage unpredictable, external events 
BASIC ANALYSIS APPROACH

MDP ANALYSIS BASED ON ALGORITHMS
The philosophy underlying MDP is that the relative impact of drivers can be used to gauge the potential for success. A predominance of success drivers in relation to failure drivers indicates an acceptable potential for success (and vice versa). After each driver is evaluated to determine its effect on the outcome, a simple algorithm is used to estimate the potential for success based on the aggregate effect of all drivers.

The analysis of drivers in MDP can be conceptually broken into the following two parts:

1. Evaluate each driver to determine the extent to which each is present. (See Section 3.3.3, Evaluate Drivers (Activity A3), for more details.)

2. Analyze the entire set of drivers to determine the potential for success. (See Section 3.3.4, Apply Analysis Algorithm (Activity A4), for more details.)

Each MOSAIC assessment protocol is based on an analysis approach that uniquely defines that protocol. The unique aspect of MDP is its algorithm-based analysis. An algorithm, as defined in this document, is defined as a finite list of well-defined instructions for accomplishing a given task that, given an initial state, will produce a defined end-state, or result.

An MDP assessment employs an algorithm that uses simple mathematics or rule-based logic to analyze a set of drivers. The objective is to use a simple set of instructions to estimate the potential for success using a predefined set of criteria (called success criteria). Several types of algorithms that can be used are discussed further in Section 3.3.4, Apply Analysis Algorithm (Activity A4). 


\section{Mission Diagnostic Protocol}

INTRODUCTION

PuRPose

OBJECTIVES

ASSESSMENT BENEFITS
This section describes MDP. It begins with an overview of MDP processes and activities. Then, details for key activities are provided along with selected examples. The examples are not meant to be allinclusive; rather they are provided to assist the reader in understanding what an activity accomplishes. Other documents that expand on this material and provide specific step-by-step directions for different activities and techniques (e.g., guidebooks, method descriptions) are planned for future publication.

An MDP assessment provides a first-pass screening of a project or process to identify any major issues or circumstances that can affect its potential for success. It can be self-applied ${ }^{4}$ by people who have experience and expertise working in the domain area being assessed.

The main objectives of an MDP assessment are to

- assess the potential for success by evaluating a small set of drivers in relation to current conditions

- determine whether the current potential for success is acceptable

- identify actions to maintain or improve the current potential for success

When used properly, an MDP assessment provides an effective diagnosis of the major issues affecting a project's or process' potential for success.

An MDP assessment provides a simple means of gauging the potential for success. It is a time- and resource-efficient way to identify major issues that can affect a project or process.

People do not need to be experts in applying and tailoring MDP assessments to obtain actionable assessment results.

An MDP assessment can be self-applied by the team responsible for overseeing or executing a project or process. Alternatively, it can be applied by a third party on behalf of the team responsible for executing a project or process. In either case, the core MDP activities performed are identical. However, the techniques and artifacts used to conduct the assessment might vary. 
ASSESSMENT

LIMITATIONS

SKILLS REQUIRED
An MDP assessment only examines the extent to which conditions are favorable for a successful outcome using a basic analysis approach. An MDP assessment only provides a "ballpark" measure of the potential for success.

Tailoring an MDP assessment (see Phase 1 on page 18 for more information) for a specific domain or problem space requires some experience and expertise. Some issues can elude detection when people use a generic set of drivers rather than a set that uniquely reflects the specific project or process being assessed.

MDP is normally performed by a small team (sometimes referred to as an analysis team) with the following skills ${ }^{5}$ :

- detailed knowledge of the domain in which the project or process is executed

- knowledge of process improvement and management

- knowledge and skills appropriate to applying MDP, such as

- analytical skills

- interviewing skills

- facilitation skills

- note-taking skills (i.e., ability to quickly record data that are identified by participants)

- communication skills

5 These skills can be distributed across a number of people in a team. Some people may have multiple skills and others may be specialists. What is important is that the team performing the MDP, as a whole, has this set of skills. 


\subsection{PROTOCOL STRUCTURE}

Phased Assessment The goal of each MOSAIC assessment protocol is to specify a seAPPROACH quence of activities that must be performed when conducting that assessment. However, an assessment must be performed within a broader context, or environment. Therefore, the protocol structure used within MOSAIC also specifies preparation and post-assessment activities. Figure 4 shows the three phases that must be completed when conducting MOSAIC assessments.

\begin{tabular}{|c|c|c|} 
Phase 1 \\
Prepare for the \\
Assessment
\end{tabular}$\quad \begin{gathered}\text { Phase 2 } \\
\text { Conduct the } \\
\text { Assessment }\end{gathered} \quad \begin{gathered}\text { Phase } 3 \\
\text { Complete Post- } \\
\text { Assessment Activities }\end{gathered} \mid$

Figure 4: Protocol Structure

PROTOCOL

DATAFLOWS
The focal point of a MOSAIC assessment protocol is a dataflow diagram. For each assessment protocol, the following diagrams are documented:

- a high-level dataflow diagram for each phase

- a detailed dataflow diagram for Phase 2

- a high-level dataflow diagram for each Phase 2 activity

Phase 2 is described in more detail than the other two phases because it specifies the distinct sequence of activities that uniquely defines the assessment approach. In other words, the unique characteristics of the assessment are embodied in its Phase 2 activity dataflow. The preparation and post-assessment activities of Phases 1 and 3 are common to all assessment protocols and do not have a unique sequence of activities associated with them. Only a top-level dataflow is presented for Phases 1 and 3. More detailed information about the structure of MOSAIC assessment protocols is presented in Appendix B: Protocol Structure and Nomenclature. 


\subsection{PREPARE FOR THE ASSESSMENT (PHASE 1)}

INTRODUCTION Phase 1 of an MDP assessment, Prepare for the Assessment, is focused on getting ready to conduct the assessment. This includes all of the planning and logistics management needed to make the assessment execution flow smoothly as well as assuring that key stakeholders provide visible support for the assessment. This preparation lays the foundation for conducting the assessment during Phase 2.

\section{ObJectives}

Phase 1 answers the following questions:

- Who is sponsoring the assessment?

- How can stakeholder sponsorship be attained?

- What is the scope of the assessment?

- What is the plan for conducting the assessment?

- How will the assessment team gain the knowledge, skills, and abilities to perform the assessment?

- What facilities and equipment are needed to conduct each assessment activity?

- What procedures, tools, and artifacts are needed to conduct each assessment activity?

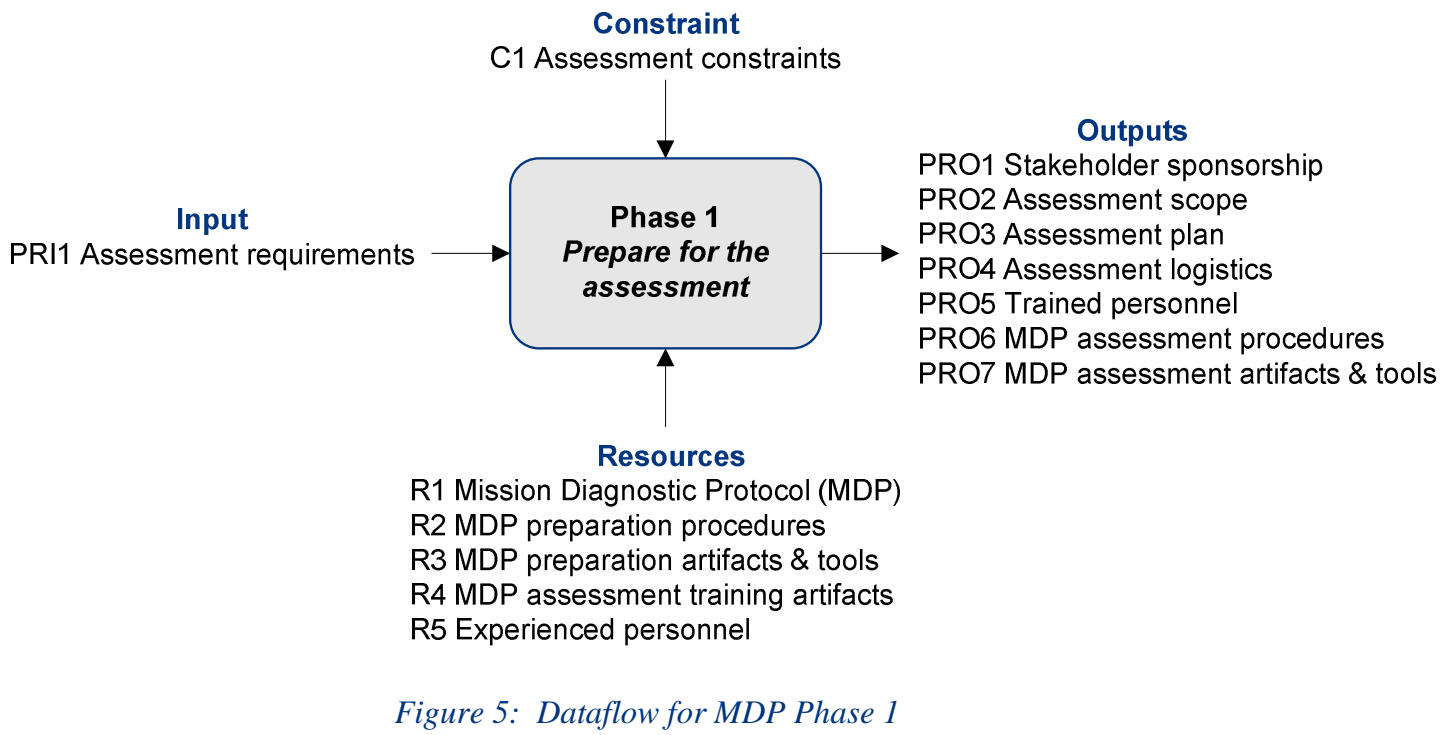



protocol phase.

\begin{tabular}{|l|l|}
\hline Type & Description \\
\hline $\begin{array}{l}\text { PRI1 Assessment require- } \\
\text { ments }\end{array}$ & $\begin{array}{l}\text { The goals of the assessment, needs of the stakeholders, and a basic descrip- } \\
\text { tion of the project or process being analyzed }\end{array}$ \\
\hline
\end{tabular}

ConstrainT

The following constraint affects execution of the activities performed during this protocol phase.

\begin{tabular}{|l|l|}
\hline Type & Description \\
\hline C1 Assessment constraints & $\begin{array}{l}\text { Any circumstances, including logistics, personnel, schedule, and cost issues, } \\
\text { that could affect assessment activities }\end{array}$ \\
\hline
\end{tabular}

RESOURCES

The following resources support execution of the activities performed during this protocol phase.

\begin{tabular}{|l|l|}
\hline Type & Description \\
\hline $\begin{array}{l}\text { R1 Mission Diagnostic } \\
\text { Protocol (MDP) }\end{array}$ & The basic approach, or framework, for conducting an MDP assessment \\
\hline $\begin{array}{l}\text { R2 MDP preparation pro- } \\
\text { cedures }\end{array}$ & Documentation that describes how to prepare for an MDP assessment \\
\hline $\begin{array}{l}\text { R3 MDP preparation arti- } \\
\text { facts and tools }\end{array}$ & $\begin{array}{l}\text { Worksheets, automated tools, and databases needed to prepare for an MDP } \\
\text { assessment }\end{array}$ \\
\hline $\begin{array}{l}\text { R4 Assessment training } \\
\text { artifacts }\end{array}$ & $\begin{array}{l}\text { Documentation and other materials used to train people how to conduct an } \\
\text { MDP assessment }\end{array}$ \\
\hline R5 Experienced personnel & People who are experienced in all phases of an MDP assessment \\
\hline
\end{tabular}

OUTPUTS

The following outputs are produced by the activities performed during this protocol phase.

\begin{tabular}{|l|l|}
\hline Type & Description \\
\hline $\begin{array}{l}\text { PRO1 Stakeholder spon- } \\
\text { sorship }\end{array}$ & $\begin{array}{l}\text { Active and visible support of the assessment by key stakeholders and decision } \\
\text { makers }\end{array}$ \\
\hline
\end{tabular}

6 Note that an existing method consistent with the protocol will include all of the procedures, artifacts, and tools required to perform the assessment. For this protocol, it is assumed a method is created as part of preparation. If a method already exists that is appropriate, then it would take the place of resources R1, R2, and R3. 


\begin{tabular}{|c|c|}
\hline Type & Description \\
\hline PRO2 Assessment scope ${ }^{7}$ & $\begin{array}{l}\text { The boundaries of the assessment, including } \\
\text { - each key objective for the project or process } \\
\text { - all activities needed to achieve the key objectives } \\
\text { - the people who have ultimate responsibility for completing or overseeing } \\
\text { each project or process activity }\end{array}$ \\
\hline PRO3 Assessment plan & $\begin{array}{l}\text { The approach for conducting the assessment, including key activities, re- } \\
\text { sources, schedule, and funding, as well as the requirements for communicating } \\
\text { results to key stakeholders after the assessment is complete }\end{array}$ \\
\hline PRO4 Assessment logistics & $\begin{array}{l}\text { The facilities and equipment needed to conduct the assessment as well as } \\
\text { communications about meeting times and locations }\end{array}$ \\
\hline PRO5 Trained personnel & $\begin{array}{l}\text { The people who are tasked with performing the assessment and are prepared } \\
\text { to conduct it }\end{array}$ \\
\hline $\begin{array}{l}\text { PRO6 MDP assessment } \\
\text { procedures }\end{array}$ & Documentation that describes how to conduct assessment activities \\
\hline $\begin{array}{l}\text { PRO7 MDP assessment } \\
\text { artifacts and tools }\end{array}$ & $\begin{array}{l}\text { Worksheets, automated tools, and databases needed to perform assessment } \\
\text { activities }\end{array}$ \\
\hline
\end{tabular}

Key Activities The following table highlights the activities performed during this protocol phase. ${ }^{8}$

\begin{tabular}{|l|l|}
\hline Activity & Description \\
\hline $\begin{array}{l}\text { Develop stakeholder spon- } \\
\text { sorship }\end{array}$ & $\begin{array}{l}\text { Meet with key stakeholders and decision makers to foster their active and visi- } \\
\text { ble support of the assessment }\end{array}$ \\
\hline $\begin{array}{l}\text { Set the scope of the as- } \\
\text { sessment }\end{array}$ & $\begin{array}{l}\text { Determine the boundaries of the assessment based on requirements and con- } \\
\text { straints (schedule, funding, logistics, contractual restrictions) }\end{array}$ \\
\hline $\begin{array}{l}\text { Develop the assessment } \\
\text { plan }\end{array}$ & $\begin{array}{l}\text { Create a plan for conducting the assessment based on its scope as well as } \\
\text { requirements and constraints (schedule, funding, etc.). }\end{array}$ \\
\hline $\begin{array}{l}\text { Coordinate logistics } \\
\text { Reserve rooms for meetings, make sure that any required equipment (e.g., } \\
\text { overhead projectors, flip charts) is available, and inform people when meetings } \\
\text { will be held }\end{array}$ \\
\hline $\begin{array}{l}\text { Train personnel } \\
\text { Ensure that people who will perform the assessment are able to effectively } \\
\text { conduct all assessment activities }\end{array}$ \\
\hline $\begin{array}{l}\text { Tailor assessment proce- } \\
\text { dures, criteria, and support- } \\
\text { ing artifacts }\end{array}$ & $\begin{array}{l}\text { Adapt all MDP assessment procedures, criteria, and supporting artifacts (e.g., } \\
\text { worksheets, templates, tools) for the circumstances and contexts in which } \\
\text { those procedures will be used }\end{array}$ \\
\hline
\end{tabular}

The scope defines which activities to include in the assessment and becomes a constraint in Phase 2 . Some aspects of a project or process might be excluded from an assessment due to contract limitations or on the basis of cost.

8 Detailed descriptions of Phase 1 activities are not provided in this document.

9 The set of drivers is considered to be an assessment artifact. Tailoring the set of drivers for a given application of MDP is completed during Phase 1. 
MDP TAILORING CONSIDERATIONS
An MDP assessment must be tailored for the context in which it is applied. The table below highlights some areas in which an MDP assessment is commonly tailored.

\begin{tabular}{|c|c|}
\hline Item & Description \\
\hline Techniques & $\begin{array}{l}\text { The specific practices used to perform protocol activities } \\
\text { Selected techniques must satisfactorily achieve the key outcomes of the as- } \\
\text { sessment protocol being implemented. }\end{array}$ \\
\hline Procedures & $\begin{array}{l}\text { The steps followed when performing a technique } \\
\text { Procedures for implementing a given technique must be consistent with the } \\
\text { objectives and requirements of that technique. They must also address any } \\
\text { constraints and unique circumstances encountered (e.g., modifying an inter- } \\
\text { view technique for use during a teleconference rather than a face-to-face inter- } \\
\text { view). }\end{array}$ \\
\hline Driver set & $\begin{array}{l}\text { The characteristics of a project or process essential for achieving its objectives } \\
\text { The cumulative effects of all drivers are analyzed to determine whether a pro- } \\
\text { ject or process has sufficient momentum toward its objectives. The driver set } \\
\text { used to assess a project or process must be tailored to accurately reflect the } \\
\text { key success characteristics of that project or process. }\end{array}$ \\
\hline Assessment criteria & $\begin{array}{l}\text { A set of measures used in various aspects of the assessment } \\
\text { An MDP assessment requires the following criteria: } \\
\text { - Driver value criteria in Activity A3 to evaluate each individual driver } \\
\text { - Success criteria in Activity A4 to determine the potential for success } \\
\text { All criteria used during an MDP assessment must reflect the requirements and } \\
\text { needs of key decision makers and stakeholders. }\end{array}$ \\
\hline Supporting artifacts & $\begin{array}{l}\text { Worksheets, templates, and tools used to support the execution of a given } \\
\text { technique } \\
\text { All supporting artifacts must } \\
\text { - be consistent with the given techniques being used } \\
\text { - } \quad \text { support the key outcomes of the assessment protocol being implemented } \\
\text { - } \quad \text { support the overall goals of the assessment }\end{array}$ \\
\hline
\end{tabular}




\subsection{CONDUCT THE ASSESSMENT (PHASE 2)}

INTRODUCTION

\section{ObJectives}

DATAFLOW

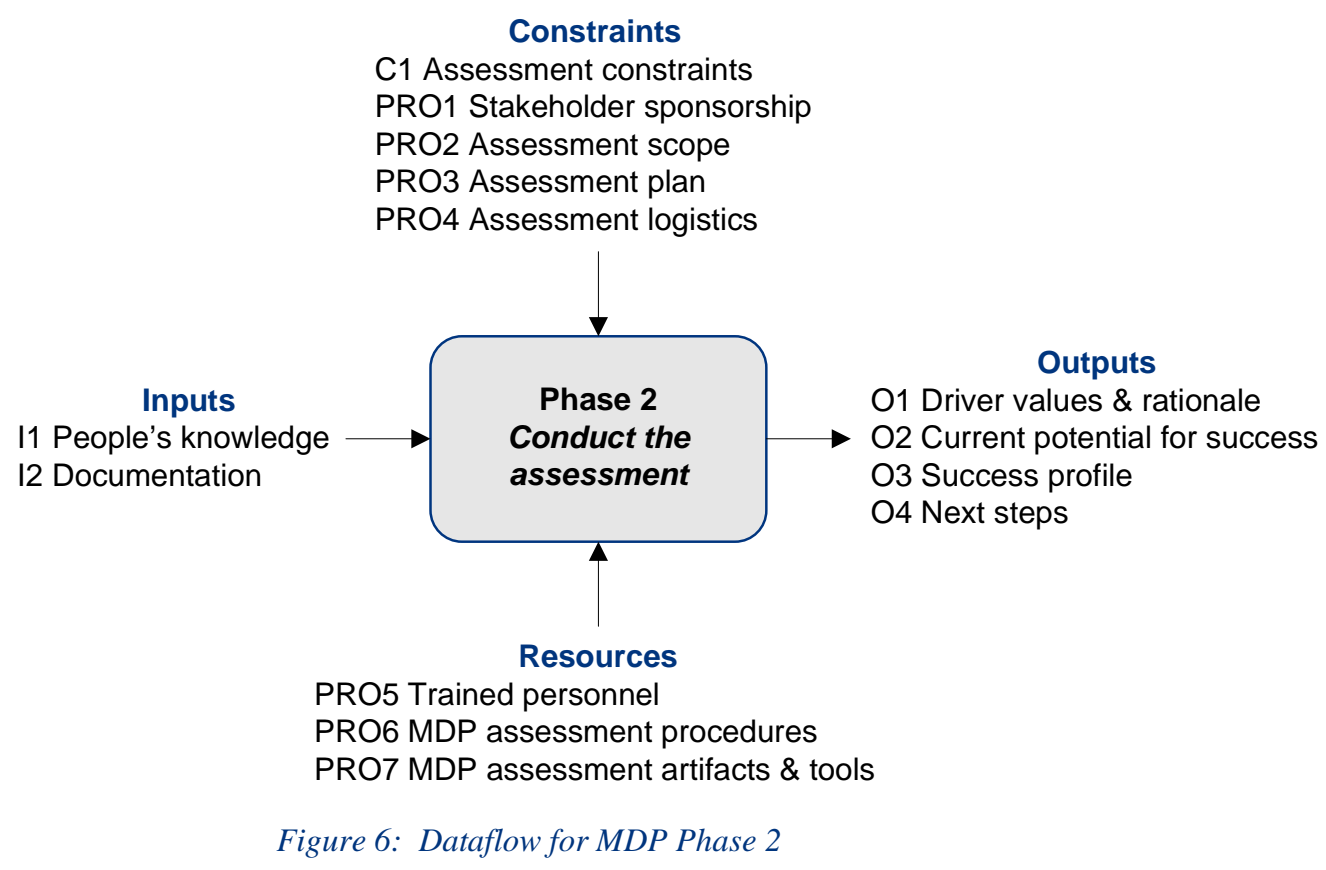

INPUTS

The following inputs are required by the activities performed during this protocol phase.

During Phase 2, the core assessment activities are performed. During this phase, data are gathered from people and generated from relevant documentation. These data are then used to evaluate a set of key drivers and ultimately determine the current potential for success. Decision-makers then determine whether the current state is acceptable and identify actions for maintaining or improving the current potential for success.

This protocol phase answers the following questions:

- What is the current potential for success?

- Is the current potential for success acceptable?

- How can the potential for success be maintained or improved over time?

The following diagram highlights the dataflow for this protocol phase.

PRO1 Stakeholder sponsorship

PRO3 Assessment plan

RO4 Assessment logistics 


\begin{tabular}{|l|l|}
\hline Type & Description \\
\hline I1 People's knowledge & $\begin{array}{l}\text { People's individual and collective perspectives, information, and opinions about } \\
\text { the project or process and its potential for success }\end{array}$ \\
\hline I2 Documentation & $\begin{array}{l}\text { Documentation that is relevant to the project or process. Examples include } \\
\text { mission statement, policies, procedures, process workflow, work products, and } \\
\text { quality assurance data. }\end{array}$ \\
\hline
\end{tabular}

CONSTRAINTs $^{10}$

The following constraints affect execution of the activities performed during this protocol phase.

\begin{tabular}{|l|l|}
\hline Type & Description \\
\hline C1 Assessment constraints & $\begin{array}{l}\text { Any circumstances, including logistics, personnel, schedule, and cost issues, } \\
\text { that could affect assessment activities }\end{array}$ \\
\hline $\begin{array}{l}\text { PRO1 Stakeholder spon- } \\
\text { sorship }\end{array}$ & $\begin{array}{l}\text { Active and visible support of the assessment by key stakeholders and decision } \\
\text { makers }\end{array}$ \\
\hline PRO2 Assessment scope & $\begin{array}{l}\text { The boundaries of the assessment, including } \\
\text { - each key objective for the project or process } \\
\text { - all activities needed to achieve the key objectives } \\
\text { the people who have ultimate responsibility for completing or overseeing } \\
\text { each project or process activity }\end{array}$ \\
\hline PRO3 Assessment plan & $\begin{array}{l}\text { The activities needed to conduct the assessment, including resources and } \\
\text { schedule needed to complete the assessment }\end{array}$ \\
\hline PRO4 Assessment logistics & $\begin{array}{l}\text { The facilities and equipment needed to conduct the assessment as well as } \\
\text { communications about meeting times and locations }\end{array}$ \\
\hline
\end{tabular}

RESOURCES $^{10}$

The following resources support execution of the activities performed during this protocol phase.

\begin{tabular}{|l|l|}
\hline Type & Description \\
\hline PRO5 Trained personnel & People who understand how to conduct the MDP assessment \\
\hline $\begin{array}{l}\text { PRO6 MDP assessment } \\
\text { procedures }\end{array}$ & $\begin{array}{l}\text { Documentation that describes how to conduct each technique associated with } \\
\text { the assessment activity }\end{array}$ \\
\hline $\begin{array}{l}\text { PRO7 MDP assessment } \\
\text { artifacts and tools }\end{array}$ & $\begin{array}{l}\text { Worksheets, automated tools, and databases needed to perform the tech- } \\
\text { niques associated with each assessment activities }\end{array}$ \\
\hline
\end{tabular}

\section{OUTPUTS}

The following outputs are produced by the activities performed during this protocol phase.

${ }^{10}$ Constraints affect all activities performed during Phase 2, while resources are used to aid the completion of all activities performed during Phase 2. The definitions for all Phase 2 constraints and resources are provided in this section only; they are not provided in the sections for individual Phase 2 activities. 


\begin{tabular}{|l|l|}
\hline Type & Description \\
\hline $\begin{array}{l}\text { O1 Driver values and ra- } \\
\text { tionale }\end{array}$ & $\begin{array}{l}\text { The current status of each driver, which includes } \\
\text { - the driver value }\end{array}$ \\
\hline $\begin{array}{l}\text { O2 Current potential for } \\
\text { success }\end{array}$ & $\begin{array}{l}\text { The current probability, or likelihood, that the desired outcome will be achieved } \\
\text { or exceeded }\end{array}$ \\
\hline O3 Success profile & $\begin{array}{l}\text { The current status of the project or process, including } \\
\text { - measure of the current potential for success }\end{array}$ \\
\hline O4 Next steps & $\begin{array}{l}\text { - measure of the desired potential for success, or success threshold } \\
\text { analysis of the gap between the current potential for success and its suc- } \\
\text { cess threshold }\end{array}$ \\
\hline
\end{tabular}

Key Activities The following table highlights the activities performed during this protocol phase. The remainder of this section provides additional details about the activities featured in the dataflow.

\begin{tabular}{|l|l|}
\hline Activity & Description \\
\hline A1 Gather data from people & $\begin{array}{l}\text { Elicit information about a project or process from people who play a role in } \\
\text { executing it and transform the information into usable data }\end{array}$ \\
\hline $\begin{array}{l}\text { A2 Generate data from } \\
\text { documentation }\end{array}$ & $\begin{array}{l}\text { Collect documentation relevant to the project or process (policies, procedures, } \\
\text { or reports) and generate usable data from that documentation }\end{array}$ \\
\hline A3 Evaluate drivers & $\begin{array}{l}\text { Establish the current conditions affecting the project or process by evaluating } \\
\text { the key drivers of success }\end{array}$ \\
\hline A4 Apply analysis algorithm & $\begin{array}{l}\text { Follow the selected analysis algorithm to estimate the current potential for suc- } \\
\text { cess }\end{array}$ \\
\hline $\begin{array}{l}\text { A5 Establish success pro- } \\
\text { file }\end{array}$ & $\begin{array}{l}\text { Generate a success profile for the project or process by } \\
\text { - setting the success threshold } \\
\text { - comparing the current potential for success to the success threshold } \\
\text { - deciding whether or not the current potential for success is acceptable }\end{array}$ \\
\hline A6 Determine next steps & \begin{tabular}{l} 
Identify actions for maintaining or improving the potential for success \\
\hline
\end{tabular}
\end{tabular}

Detalled Dataflow $\quad$ Figure 7 provides a detailed dataflow for MDP Phase 2. 


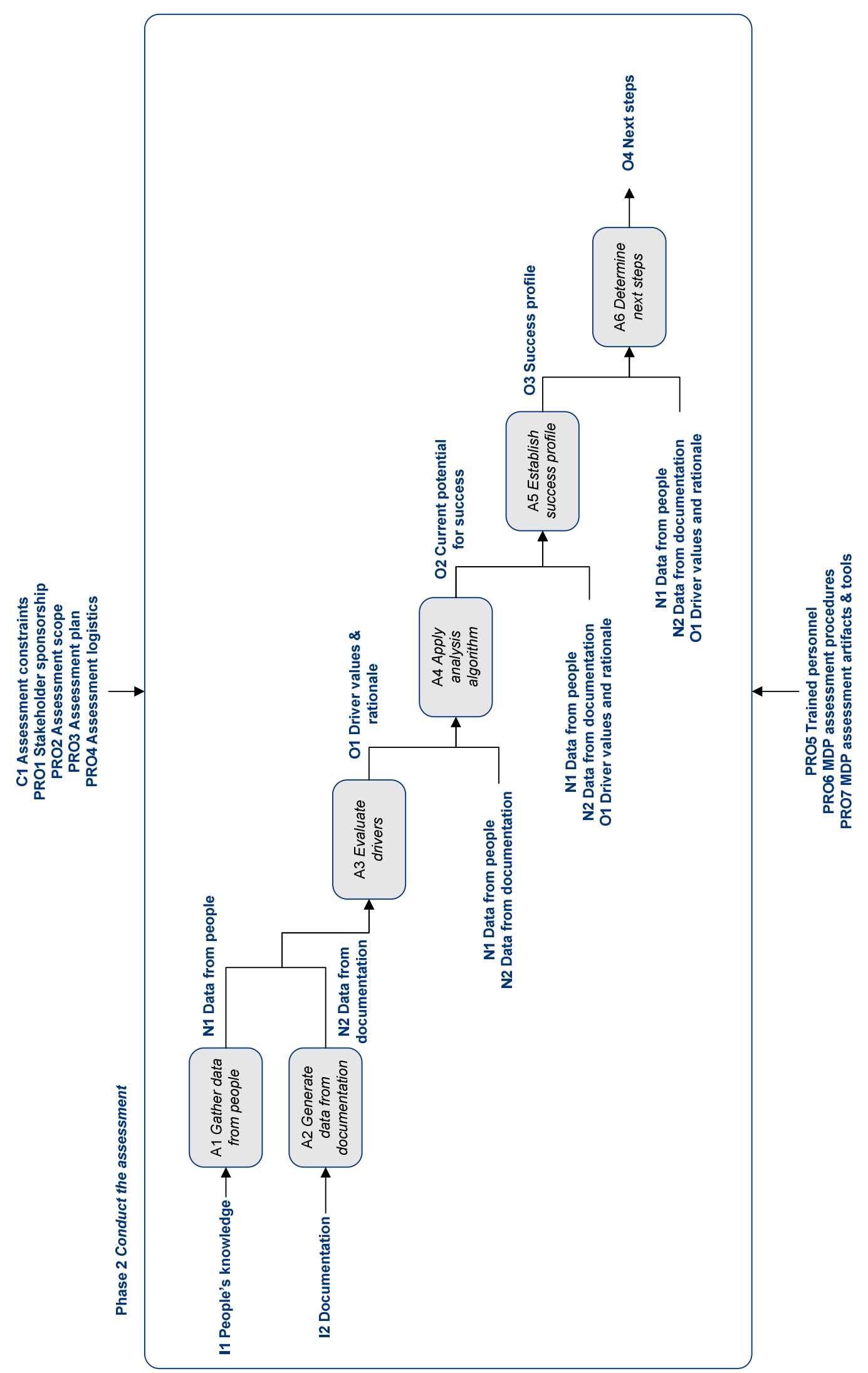

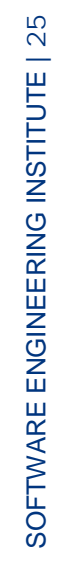

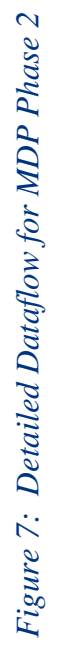




\subsubsection{GATHER DATA FROM PEOPLE (ACTIVITY A1)}

INTRODUCTION

ObJectives

\subsubsection{Dataflow}

In order to analyze the potential for success, you must first gather relevant information. One key source of information is the people who perform the activities that support the project or process (e.g., software developers creating a product, network experts responding to security incidents). This protocol activity (1) elicits information from selected personnel who play a role in executing a project or process and (2) transforms their tacit knowledge into usable data. Information that is gathered from people must support the analysis and be in a form that is compatible with chosen techniques.

This activity answers the following questions:

- What conditions and events are driving the project or process toward a successful outcome?

- What conditions and events are driving the project or process toward an unsuccessful, or failed, outcome?

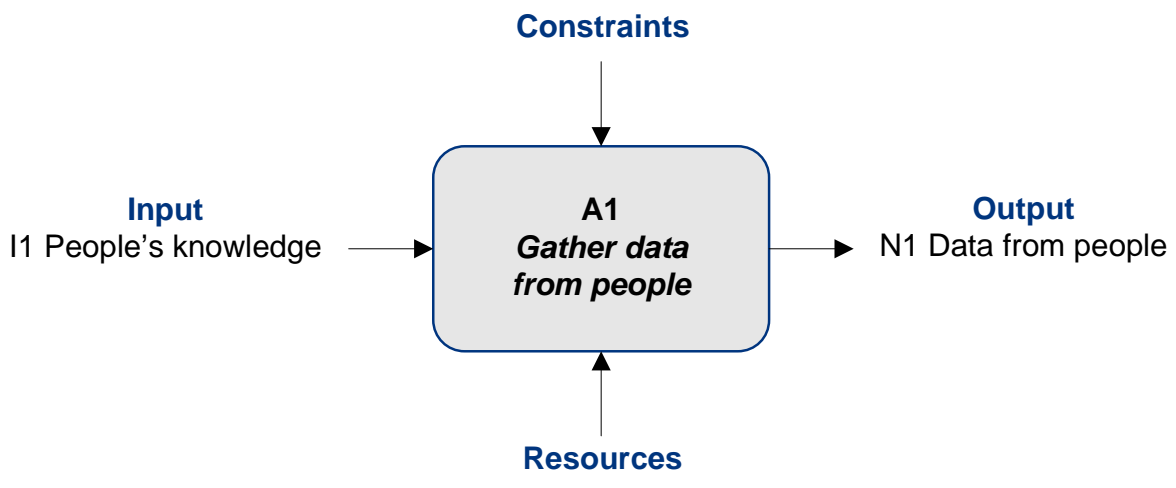

Figure 8: Inputs and Outputs for Activity A1

\begin{tabular}{|l|l|}
\hline Input and Output & Description \\
\hline I1 People's knowledge & $\begin{array}{l}\text { People's individual and collective perspectives, information, and opinions about } \\
\text { the project or process and its potential for success }\end{array}$ \\
\hline N1 Data from people & $\begin{array}{l}\text { Usable data about a project or process based on individual and group perspec- } \\
\text { tives, information, and opinions about the project or process and its potential for } \\
\text { success }\end{array}$ \\
\hline
\end{tabular}




\subsubsection{Techniques}

TECHNIQUES

WORKSHOPS

INTERVIEWS

SURVEYS
The techniques chosen for this protocol activity depend upon the nature of the project or process being assessed, the knowledge, skills, and abilities of the people who are performing the assessment, as well as organizational practices, culture, and constraints. Several techniques can be employed to collect data from people. Some of the more common data collection techniques include workshops, interviews, and surveys. Each is briefly described below.

A workshop is a facilitated session that is usually focused on solving one or more issues or problems. The facilitator(s) and participants work together when investigating the issues or problems in a workshop. Workshops tend to foster a collaborative environment.

An interview is a facilitated session where participants answer a series of specific questions asked by one or more interviewers. An interview tends to be more formal than a workshop and is normally focused on data elicitation rather than problem solving.

A survey is a time-effective way to gather data from a large group of people. Respondents are provided with a list of written questions and a set of instructions for completing the survey. In most cases, people responding to a survey have little interaction with those who are collecting the information, making surveys an impersonal means of collecting data. During an interview session, a survey can be combined with a follow-on discussion to stimulate discussion, clarify survey answers, identify conflicts, and elicit issues not captured by the survey. 
Preliminary Data

ANALYSIS
A considerable amount of data can be collected during workshops and interviews; not all of that data will be relevant to analyses that will be performed later. Sometimes it is prudent to perform a preliminary analysis of data to eliminate extraneous data. Subsequent analyses can often be conducted more efficiently and effectively when extraneous data have been removed from the input data set. Preliminary data analysis is an optional, first-pass analysis to reduce the amount of data, clarify uncertainty, eliminate non-useful data, and identify missing or inadequate data.

\subsubsection{Examples}

\section{EXAMPLe Driver Set}

During Phase 1, a set of drivers is tailored for the project or process that is being assessed. In an MDP assessment, each driver is characterized by a yes/no question, where an answer of yes denotes a success driver and an answer of no denotes a failure driver. Example 1 below illustrates a set of driver questions. The driver questions can be embodied in surveys or used as interview questions to support data gathering efforts.

\section{Driver Questions}

1. Are project goals realistic and well-articulated?

2. Are communication and information sharing about project activities effective?

3. Are customer requirements and needs well understood?

4. Are organizational and political conditions facilitating completion of project activities?

5. Is the project plan sufficient?

6. Does project management facilitate execution of tasks and activities?

7. Is task execution efficient and effective?

8. Is staffing sufficient to execute all project activities?

9. Are the technological and physical infrastructures adequate to support all project activities?

10. Are changing circumstances and unpredictable events effectively managed?

Example 1: Set of Drivers 
CONDUCTING AN INTERVIEW
During an interview, people are asked a series of questions and their responses are recorded. Interview questions for MDP Activity A1 are often oriented around the set of drivers. Interview participants are asked each driver question. They provide their response to each question as well as their rationale. Example 2 is an example set of data for one driver question gathered from an interview session.

Question
$\begin{aligned} & \text { 1. Are project goals realistic } \\ & \text { and well-articulated? }\end{aligned}$
Rationale
There were goals published 18 months ago, but those don't seem to be what
managers want now. I have not seen anything recent. I have heard conflicting
goals from the hardware lead vs. the software lead. At our last project meet-
ing we were told that the CIO wants this delivery schedule decreased by 6
months - and that means we can't meet customer requirements.

Example 2: Data from One Person for One Driver 


\subsubsection{GENERATE DATA FROM DOCUMENTATION (ACTIVITY A2)}

INTRODUCTION

OBjectives

\subsubsection{Dataflow}

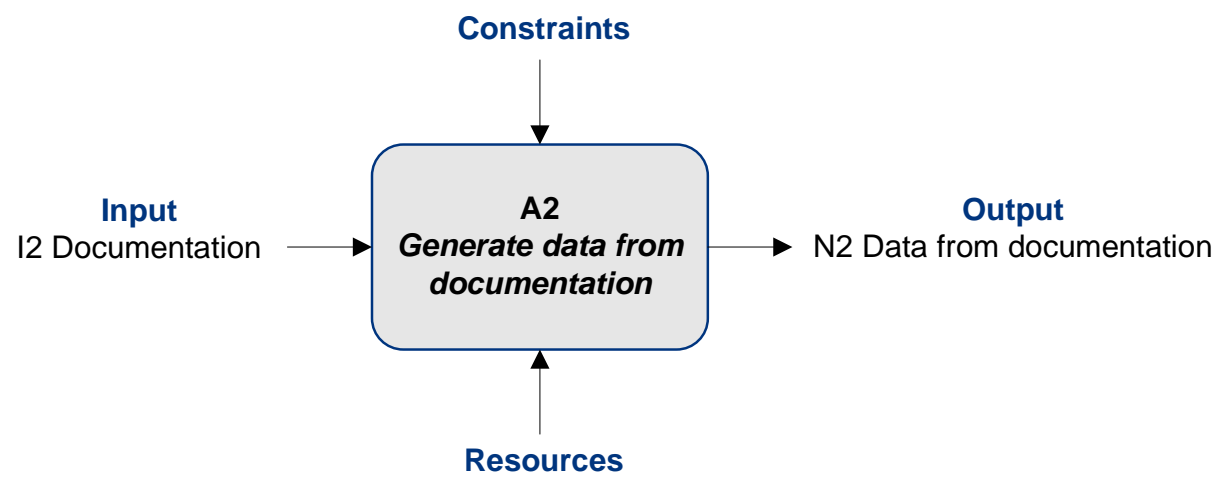

Figure 9: Inputs and Outputs for Activity A2

\begin{tabular}{|l|l|}
\hline Input and Output & Description \\
\hline I2 Documentation & $\begin{array}{l}\text { Documentation that is relevant to the project or process. Examples include } \\
\text { mission statement, policies, procedures, process workflow, work products, and } \\
\text { quality assurance data. }\end{array}$ \\
\hline $\begin{array}{l}\text { N2 Data from documenta- } \\
\text { tion }\end{array}$ & $\begin{array}{l}\text { Usable data about a project or process that is distilled from documentation, } \\
\text { such as policies, procedures, work products, and quality assurance data }\end{array}$ \\
\hline
\end{tabular}




\subsubsection{Techniques}

TECHNIQUES

DOCUMENT IDENTIFICATION

Document ANALysis
The following two classes of techniques are normally employed when conducting this protocol activity: (1) techniques used to identify documents that are relevant to the project or process and (2) techniques used to analyze those documents and produce data that are pertinent to subsequent MDP assessment activities.

The goal when collecting documents is to gather written information, such as policies, procedures, reports, and work products, that provide insight into how a project or process is managed and executed. When you gather documentation, you can follow one of two basic strategies. You can develop a list of documents that you want to review and then ask people to provide you with the documents on the list. Alternatively, you can ask for all documentation related to the project or process that you are evaluating.

You also have options related to when you ask for documentation. You could ask for documentation during Prepare for the Assessment (Phase 1) when you are getting ready to conduct the evaluation. This approach allows you to review the documents before you meet with people who work on the project or process. Alternatively, you can ask for relevant documents when you meet with people during Gather Data from People (Activity A1).

Document analysis involves reviewing documentation that you have gathered during the assessment. If you collect all of the documents you originally identified, you might need to sort through the documents to determine which are actually relevant to the assessment.

When you review a given document, you normally frame the analysis around an explicit set of guidelines or questions (usually related to the success and failure drivers). The guidelines or questions you use must be appropriate for generating sufficient data about the specific subject or problem area being investigated. Alternatively, you can use implicit guidelines during document analysis. Here, you use your expertise and experience to look for data that would be useful to the assessment. Overall, this technique provides a first-pass analysis that transforms raw, unfiltered information into data that are usable during the assessment. 


\subsubsection{Examples}

Key Questions FOR

ANALYZING

DOCUMENTS
Data generated from analyzing documents are usually structured around the driver questions. The following questions are examples that can be used to frame the document analysis:

- What information from the document supports an answer of yes to each driver question?

- What information from the document supports an answer of no to each driver question?

- What other information or context is relevant to each driver question?

Analyzing a Project

PLAN

Example 3 depicts the results for one driver question based on an analysis of a project plan.

Document: Project Plan, dated August 25, 2007

1. Are project goals realistic and well-articulated?

Information supporting an answer of Yes

Specific project goals related to cost, schedule, quality, and customer satisfaction are documented in the project plan for the initial release and the first scheduled update. All project personnel have access to the project plan.

Information supporting an answer of No

The schedule has been reduced since the plan was written. The goals have not been adjusted accordingly. The reduction in schedule does not appear to be feasible without commensurate adjustments in cost and quality.

Other relevant data

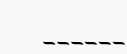

Example 3: Driver Analysis 


\subsubsection{EVALUATE DRIVERS (ACTIVITY A3)}

INTRODUCTION

OBjectives

\subsubsection{Dataflow}

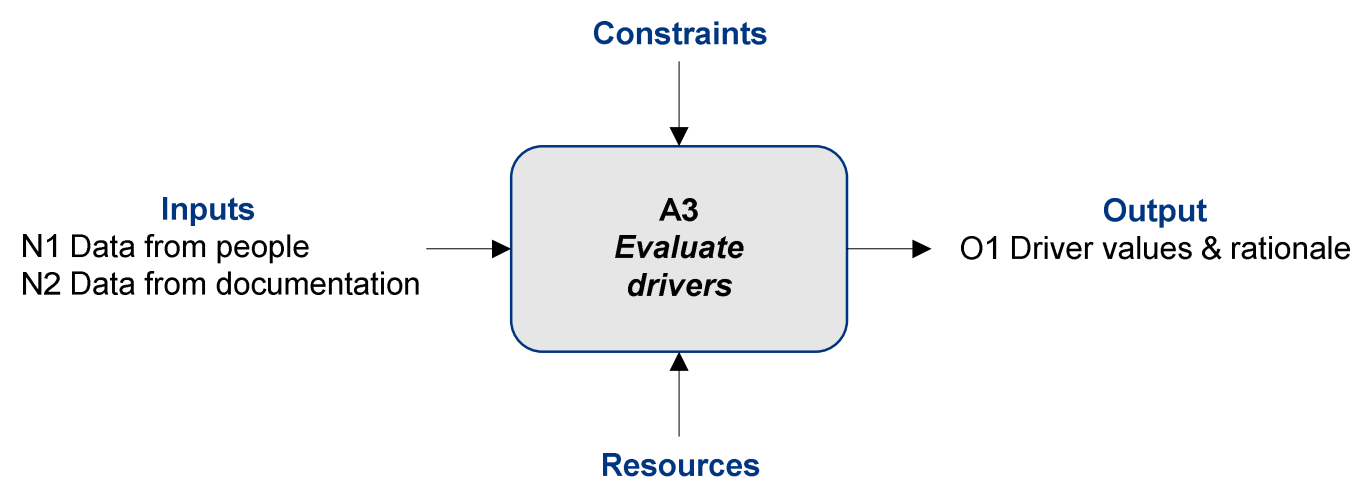

Figure 10: Inputs and Outputs for Activity A3

\begin{tabular}{|l|l|}
\hline Inputs and Output & Description \\
\hline N1 Data from people & $\begin{array}{l}\text { Usable data about a project or process based on individual and group perspec- } \\
\text { tives, information, and opinions about the project or process and its potential for } \\
\text { success }\end{array}$ \\
\hline $\begin{array}{l}\text { N2 Data from documenta- } \\
\text { tion }\end{array}$ & $\begin{array}{l}\text { Usable data about a project or process that is distilled from documentation, } \\
\text { such as policies, procedures, work products, and quality assurance data }\end{array}$ \\
\hline $\begin{array}{l}\text { O1 Driver values and ra- } \\
\text { tionale }\end{array}$ & $\begin{array}{l}\text { The current status of each driver, which includes } \\
\text { the driver value }\end{array}$ \\
\hline
\end{tabular}

This protocol activity evaluates the key drivers of success for the given project or process. These drivers are used to estimate the degree of momentum toward project or process objectives. Each driver is evalumine its effect on the outcome. Data that were collected from people and documentation during Activities A1 and A2 are used as input when evaluating drivers.

This activity answers the following questions:

- How is each driver affecting the outcome?

- Which drivers are acting as success drivers? Why?

- Which drivers are acting as failure drivers? Why? ated against a set of criteria, called driver evaluation criteria, to deter-

Resources 


\subsubsection{Techniques}

TECHNIQUES

Data ANALYSIS

Group DeCISION

MAKING

\subsubsection{Examples}

Driver Values
The techniques employed when conducting this protocol activity depend upon the knowledge, skills, and abilities of the people who are performing the assessment. Evaluating drivers generally requires techniques for analyzing data that have been collected during earlier activities. In collaborative settings where a team is evaluating drivers, group decision-making techniques can also be effective.

Each driver represents a key characteristic of a project or process that is essential for a successful outcome. When you evaluate a driver, you must rely on the data that have been gathered from people and generated from documentation. Data analysis techniques used to support this protocol activity enable you to

- consider the range of possible values for each driver, based on the relevant value criteria

- decide which value is most appropriate for each driver

- articulate a rationale for selecting each value

When evaluating drivers in a group setting, you can use techniques to facilitate decision-making activities. For example, voting techniques, such as multi-voting, can help a group sort through differences and reach consensus.

Although a driver is characterized by a yes/no question, some degree of ambiguity or uncertainty regarding the answer can exist. The range of answers for a driver, called driver values, reflects this inherent uncertainty. Example 4 depicts a driver question and its range of values.

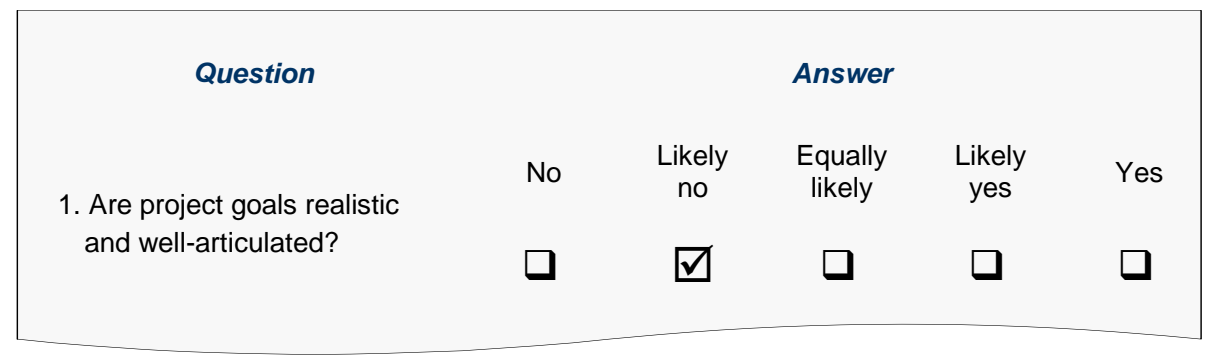

Example 4: Driver and Range of Values 
Driver Value

Criteria
People responding to driver questions need to interpret the underlying meaning of each possible answer (i.e., each driver value). Driver value criteria provide a definition for each value. The criteria enable people to understand what is implied by each potential answer for a driver question. Example 5 provides an example set of criteria that define the range of values for each driver.

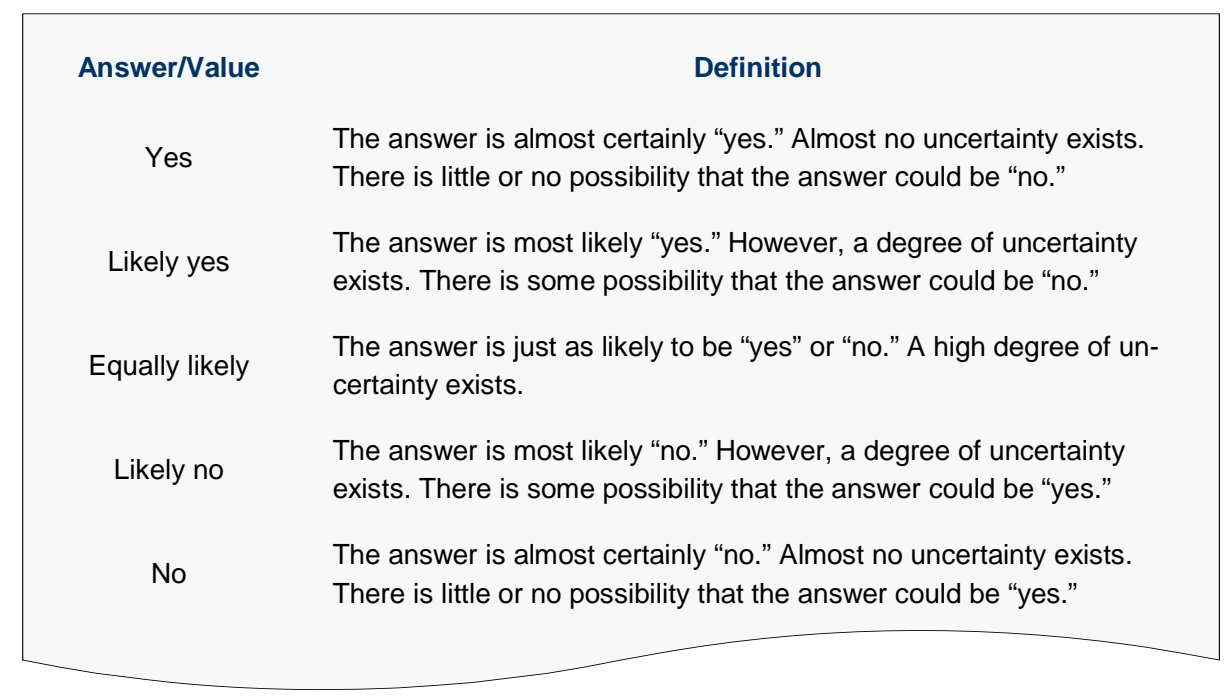

Example 5: Criteria for Driver Values
TAILORING DRIVER Value Criteria

Evaluated Drivers
The criteria for evaluating a driver can be tailored for the given assessment. For example, the criteria in Example 5 are based on a fivepoint scale. This type of scale allows decision-makers to incorporate different levels of uncertainty in their answers. More or less than five answers can be incorporated into the analysis when appropriate.

Each driver is evaluated using the selected scale using all of the information gathered in previous activities, including the driver answers from project personnel. In Example 56 below, the following final answer has been selected: likely no. This means the goals being pursued by the project are most likely unrealistic or not well understood by staff. The rationale for the answer is also documented. 


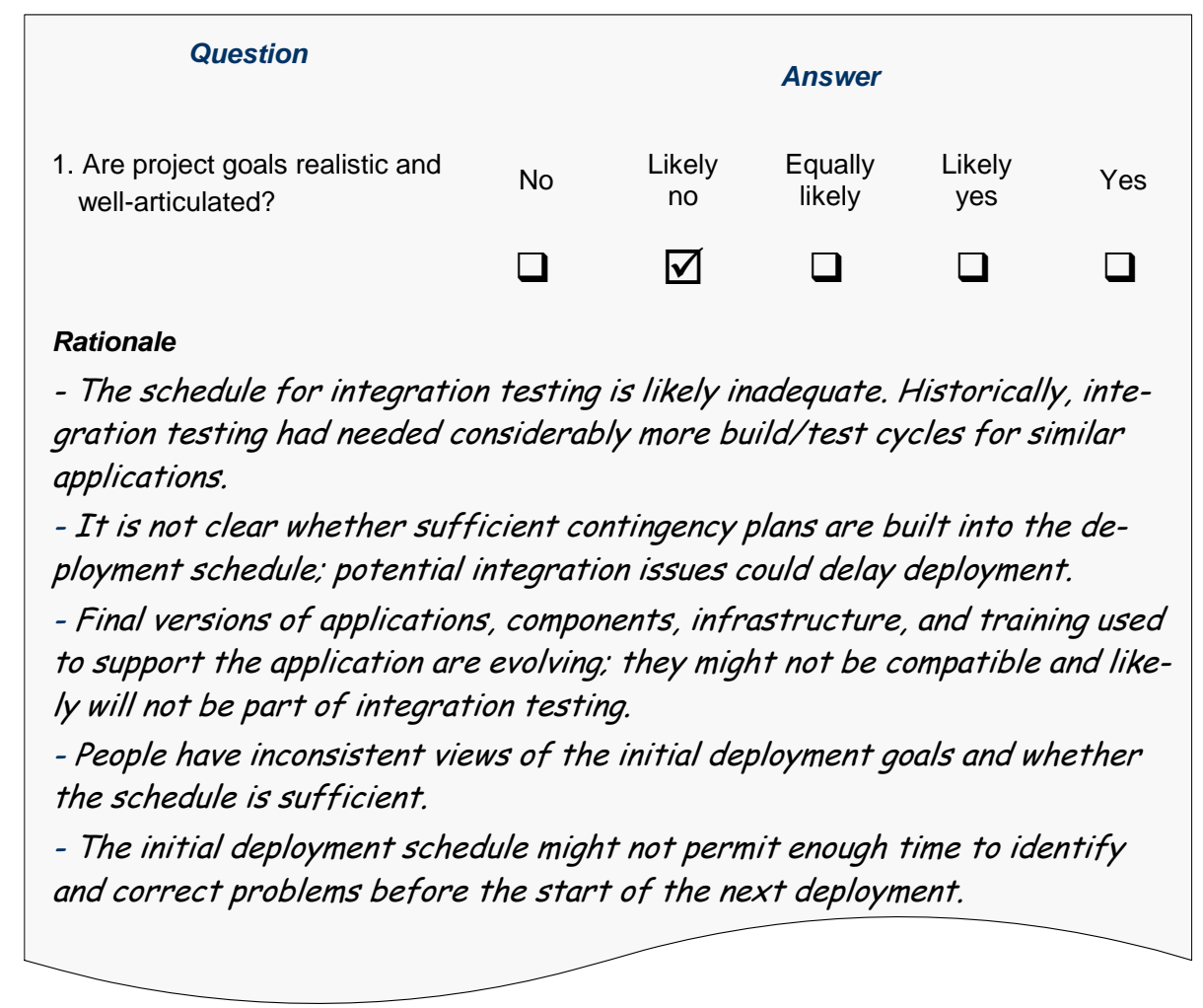

Example 6: Evaluated Driver

Driver Values and SCORES ${ }^{11}$

When the algorithm used to assess the potential for success employs simple mathematics (in Activity A4), you must also assign a number, called a driver score, to each driver value. Example 7 illustrates this concept. Each value in the figure represents the approximate probability that the driver is present. For this example, Likely no equates to a score of 0.25 , which represents a $25 \%$ likelihood that goals are realistic and well articulated.

Question

1. Are project goals realistic and well-articulated?

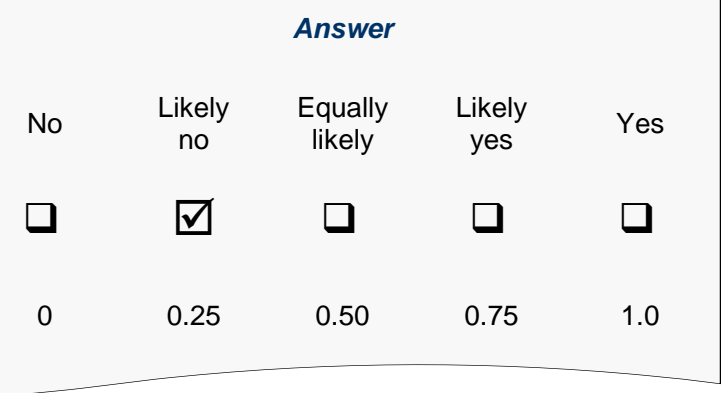

Example 7: Driver Values and Scores

11 It might seem simpler to assign numbers directly instead of answering yes/no answers. However, experience shows that many people have trouble assigning numbers directly. These people find it easier to answer the question "Are project goals realistic and well-articulated?" with "yes" or "no" rather than translating that answer into a number. If preferred, you can directly assign a score when evaluating drivers. 


\subsubsection{APPLY ANALYSIS ALGORITHM (ACTIVITY A4)}

INTRODUCTION

OBJECTIVE

\subsubsection{Dataflow}

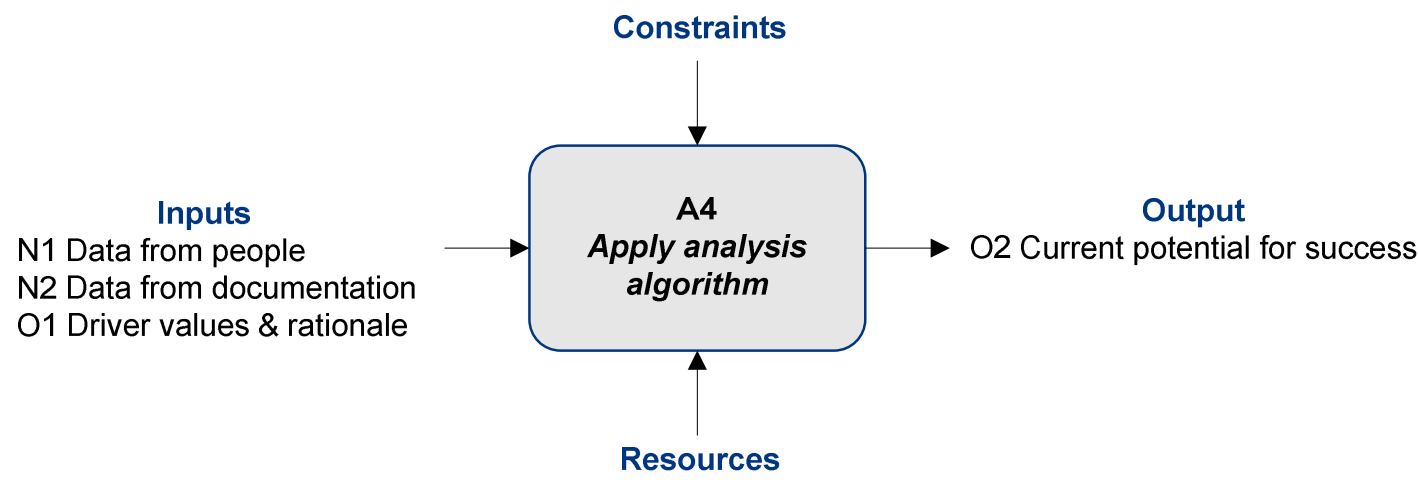

Figure 11: Inputs and Outputs for Activity A4

\begin{tabular}{|l|l|}
\hline Inputs and Output & Description \\
\hline N1 Data from people & $\begin{array}{l}\text { Usable data about a project or process based on individual and group perspec- } \\
\text { tives, information, and opinions about the project or process and its potential for } \\
\text { success }\end{array}$ \\
\hline $\begin{array}{l}\text { N2 Data from documenta- } \\
\text { tion }\end{array}$ & $\begin{array}{l}\text { Usable data about a project or process that is distilled from documentation, } \\
\text { such as policies, procedures, work products, and quality assurance data }\end{array}$ \\
\hline $\begin{array}{l}\text { O1 Driver values and ra- } \\
\text { tionale }\end{array}$ & $\begin{array}{l}\text { The current status of each driver, which includes } \\
\text { the driver value }\end{array}$ \\
\hline $\begin{array}{l}\text { O2 Current potential for } \\
\text { success }\end{array}$ & $\begin{array}{l}\text { A qualitative measure of the current probability, or likelihood, that the desired } \\
\text { outcome will be achieved or exceeded }\end{array}$ \\
\hline
\end{tabular}




\subsubsection{Techniques}

TECHNIQUES

MATH-BASED

ALGORITHMS

RULE-BASED

ALGORITHMS
The following two types of algorithms are normally employed when conducting this protocol activity: (1) algorithms that use simple mathematics and (2) algorithms that use rule-based logic.

A math-based algorithm employs simple mathematics to determine the potential for success. Before using this type of algorithm, you must first assign a driver score, or number, to each driver value in the set prior to using the algorithm. The algorithm then determines the potential for success using the driver values and predefined success criteria. Math-based algorithms normally rely upon one or more of the following basic approaches:

- aggregate driver score

- weighted aggregate driver score

- mean driver score

- median driver score

This technique employs rule-based logic to determine the potential for success. A set of rules uniquely defines each measure in the predefined success criteria for the project or process. This technique applies the rules embodied in the success criteria to a set of driver values to determine the potential for success. 


\subsubsection{Examples}

SELECting A Driver

ANALYSIS APPROACH
As part of tailoring or adapting MDP to the specific needs of an assessment, you need to select an analysis approach. Different approaches for analyzing drivers can be used in different situations. In general, you should consider the following:

- the goals of a particular assessment

- the specific drivers being used

- the experience and expertise of people conducting the assessment

In some cases, one analysis approach will be sufficient for an assessment. In other instances, you might decide to use multiple approaches to analyze a set of drivers (e.g., using both aggregate driver score and rule-based logic). Employing more than one approach provides you with multiple views of the data, which, in some instances, can enhance decision making.

Example 8 provides a set of driver values from Activity A3. The examples later in this section reference the driver scores in Example 8.

\section{Driver}

1. Are project goals realistic and well-articulated?

2. Are communication and information sharing about project activities effective?

3. Are customer requirements and needs well understood?

4. Are organizational and political conditions facilitating completion of project activities?

5. Is the project plan sufficient?

6. Does project management facilitate execution of tasks and activities?

7. Is task execution efficient and effective?

8. Is staffing sufficient to execute all project activities?

9. Are the technological and physical infrastructures adequate to support all project activities?

10. Are changing circumstances and unpredictable events effectively managed?

Total

\section{Score}

0.25

Example 8: Evaluated Driver Set 
Success criteria define the measures used to characterize the potential for success. Each measure in the criteria specifies the conditions that must be satisfied for that measure. In addition, it is important to note that all measures in the criteria must be mutually exclusive. Success criteria are a vital part of MDP because they enable people to interpret a set of drivers. Example 9 depicts success criteria that can be used with an aggregate driver score. When you compare the aggregate driver score from Example 8 to the success criteria in Example 9, you can then determine that the potential for success for this example is low.

\begin{tabular}{|llr|}
\hline Measure & \multicolumn{1}{c}{ Description } & Range \\
Excellent & Conditions are extremely favorable for a successful outcome. & $8.5-10$ \\
High & Conditions are favorable for a successful outcome. & $6.5-8.4$ \\
Borderline & Conditions are mixed, making the outcome uncertain. & $3.5-6.4$ \\
Low & Conditions are not favorable for a successful outcome. & $1.5-3.4$ \\
Minimal & Conditions are extremely unfavorable for a successful outcome. & $0-1.4$ \\
\hline
\end{tabular}

Example 9: Success Criteria

TAILORING SUCCESS Criteria
Success criteria must be tailored appropriately for each context in which they are used. When tailoring success criteria, you must consider the following three requirements:

1. Success criteria must be suitable for the analysis approach being used. For example, the criteria in Example 8 are appropriate for an analysis approach using aggregated driver scores.

2. The measurement scale included in success criteria should reflect the needs of decision makers. A two-point scale is simple, but generally provides insufficient differentiation for decision-makers. A twenty-point scale provides considerable differentiation but can be difficult to use with any degree of accuracy.

3. The success criteria must reflect the context in which they are applied. For example, decision makers with little tolerance for risk may want a narrower range for the measure of Excellent $(9.5$ - 10). 
- aggregate driver score

- weighted driver score

- mean driver score

- median driver score

- rule-based logic

AgGregate Driver SCORE
WEIGHTED

AgGregate Driver SCORE
The aggregate driver score is the sum of the scores for all drivers. After you determine the aggregate driver score, you then compare it to a set of predefined success criteria (as shown in Example 9) to determine the potential for success. An analysis approach based on the aggregate driver score is a straightforward way of analyzing a set of drivers. It allows you to quickly gauge the potential for success based on the relative influence of all drivers. Example 10 shows the aggregate driver score for the example set of drivers presented in Example 8.

\section{Aggregate Driver Score}

$0.25+0+0.5+0+0.25+0.25+0.75+0.25+0.25+0.25=\mathbf{2 . 7 5}$

\section{Example 10: Aggregate Scoring}

To determine a weighted aggregate driver score, you assign a weighting factor to each driver. Weighing factors are based on the relative influence of drivers on the potential for success. When a weighting factor is applied to a driver, its score is multiplied by that weighting factor. A total weighted, or adjusted, aggregate driver score is then calculated by adding the weighted scores for all drivers. Example 11 shows an example of applying weighting factors where drivers 1,4 , and 7 from Example 8 are judged to have twice the influence of the other drivers. The weighted aggregate driver score is then compared to the appropriate success criteria (example not provided) to determine the potential for success.

Weighted Driver Score

$2(0.25)+0+0.5+2(0)+0.25+0.25+2(0.75)+0.25+0.25+0.25=3.75$

Example 11: Weighted Aggregate Scoring 
Effective

APPLICATIONS OF

WEIGHTING FACTORS

Mean Driver Score

Median Driver

SCORE
Effective use of weighting factors requires considerable experience and expertise in applying MDP. It also requires you to have a considerable experience with, and understanding of, the project or program being evaluated. Without appropriate experience and expertise, people tend to weight drivers improperly, which can skew results.

The mean driver score, also known as the average driver score, is determined by adding all of the driver values and dividing by the number of drivers. Example 12 shows the mean driver score for the set of drivers presented in Example 8. The mean value for the set of drivers is compared to the appropriate success criteria (example not provided) to determine the potential for success.

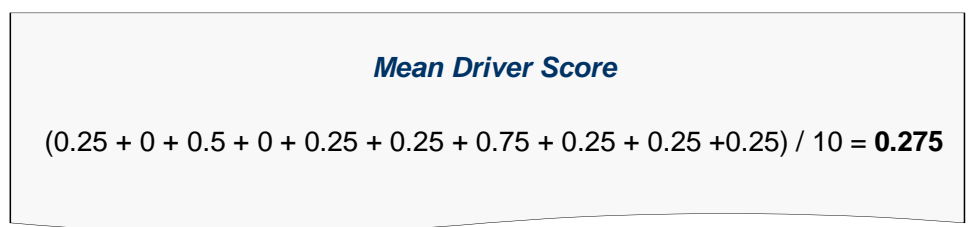

Example 12: Mean Scoring

The median is the midpoint in a series of numbers. Half of the numbers are above the median value, while the other half are below. The first step when determining the median for a set of data is to arrange all of the numbers in order, from smallest to largest. The median is the middle number in the series. Example 13 shows the data from Example 8 arranged from smallest to largest. In this example, 10 driver scores are included in the series, so the median is the average of the fifth and sixth scores. The median driver score is compared to the appropriate success criteria (example not provided) to determine the potential for success.

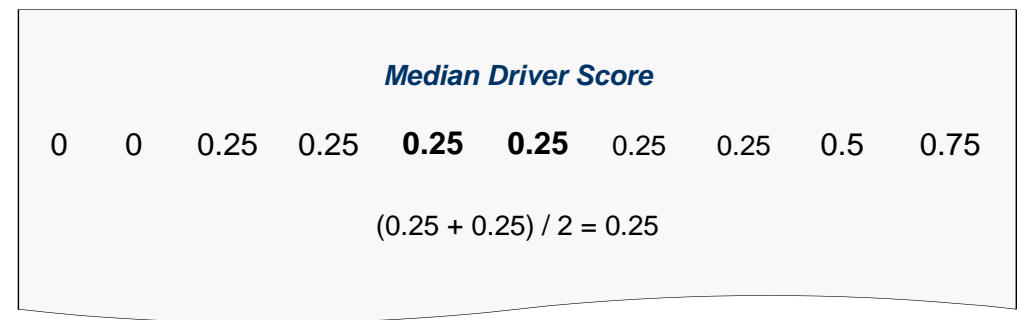

Example 13: Median Scoring 
ALGORITHMS WITH RULE-BASED LOGIC
Rule-based algorithms differ from the other approaches profiled in this section because it does not require you to apply mathematical operations to driver scores. Instead, a set of rules uniquely defines each measure in the success criteria. This technique applies the rules embodied in the success criteria to a set of driver values to determine the potential for success. Each measure in the criteria corresponds to one or more rules that specify a set of conditions (related to the drivers) unique to that measure. Consider the following example where an $e x$ cellent potential for success requires meeting the following two rules:

- At least seven driver answers must be yes.

- No driver can have an answer of no, likely no, or equally likely.

Rules for other measures in the success criteria would be documented in a similar manner. This analysis approach is considerably more complex than the others. When using rule-based logic, you must ensure that the rules for all measures (1) are mutually exclusive and (2) appropriately reflect the decision-makers tolerance for risk. 


\subsubsection{ESTABLISH SUCCESS PROFILE (ACTIVITY A5)}

INTRODUCTION

OBJectives

\subsubsection{Dataflow}

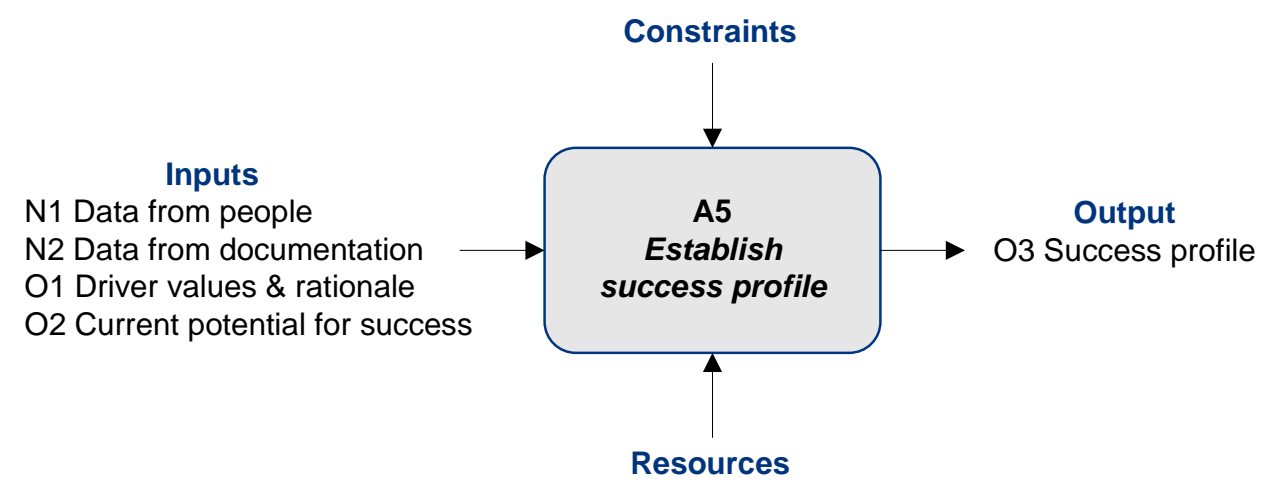

Figure 12: Inputs and Outputs for Activity A5

12 While it may seem logical to assume that the desired potential for success is always high, that is not always true. For example, a research and development project might begin with a low potential for success. A research and development project is inherently risky, which leads to a low potential for success. However, to achieve an opportunity, management might decide to accept the low potential for success. People must use common sense when setting the desired potential for success. Every project has some amount of uncertainty; how much uncertainty is acceptable to stakeholders helps determine the desired potential for success. 


\begin{tabular}{|l|l|}
\hline Inputs and Output & Description \\
\hline N1 Data from people & $\begin{array}{l}\text { Usable data about a project or process based on individual and group perspec- } \\
\text { tives, information, and opinions about the project or process and its potential for } \\
\text { success }\end{array}$ \\
\hline $\begin{array}{l}\text { N2 Data from documenta- } \\
\text { tion }\end{array}$ & $\begin{array}{l}\text { Usable data about a project or process that is distilled from documentation, } \\
\text { such as policies, procedures, work products, and quality assurance data }\end{array}$ \\
\hline $\begin{array}{l}\text { O1 Driver values and ra- } \\
\text { tionale }\end{array}$ & $\begin{array}{l}\text { The current status of each driver, which includes } \\
\text { the driver value }\end{array}$ \\
\hline $\begin{array}{l}\text { O2 Current potential for } \\
\text { success }\end{array}$ & $\begin{array}{l}\text { A qualitative measure of the current probability, or likelihood, that the desired } \\
\text { outcome will be achieved or exceeded }\end{array}$ \\
\hline O3 Success profile & $\begin{array}{l}\text { The current status of the project or process, including } \\
\text { - measure of the current potential for success } \\
\text { - measure of the desired potential for success, or success threshold } \\
\text { - } \begin{array}{l}\text { analysis of the gap between the current potential for success and its suc- } \\
\text { cess threshold }\end{array}\end{array}$ \\
\hline
\end{tabular}

\subsubsection{Techniques}

TECHNIQUES

The following types of techniques are used when establishing a success profile:

- establishing the success threshold

- data collection

- gap analysis

- group decision making 
ESTABLISHING THE SUCCESS THRESHOLD

Data Collection

GAP ANALYSIS

Group DeCISION MAKING
The potential for success characterizes the likelihood, or probability, that the desired outcome will be achieved or exceeded. The success threshold is the desired, or target, probability for the project or process from the perspective of key stakeholders (e.g., a 15\% return on investment, $90 \%$ satisfied customers, $80 \%$ of functional requirements delivered). It reflects stakeholders' overall tolerance for risk. Techniques for establishing the success threshold enable you to

- review the data that you collected from each key stakeholder

- identify which stakeholders are the key decision makers for the project or process

- determine how much risk or uncertainty key decision makers will tolerate

- select the probability that most appropriately reflects the perspective of key stakeholders

- confirm the success threshold with key stakeholders prior to performing the gap analysis, if needed

You might collect all of the data you need to establish the success threshold when meeting with stakeholders during preparation. ${ }^{13}$ Alternatively, you might get the information you need during Activity A1. Sometimes, you will find that you need to collect additional data when you are ready to set the success threshold during this protocol activity. You can use several techniques to collect data from key stakeholders. See Activity A1 for a summary of data collection techniques.

Gap-analysis techniques are used to compare the current potential for success to its success threshold. These techniques are useful when determining whether the current potential for success is acceptable or not. Gap-analysis techniques also determine which conditions are contributing to the gap and how.

When analyzing the potential for success in a group setting, you can use techniques to facilitate decision-making activities. For example, voting techniques, such as multi-voting, can help a group sort through differences and reach consensus.

\footnotetext{
13 The success threshold must be set by the time this activity is performed. However, you can set the success threshold earlier in the assessment, for example during the Phase 1 preparation activities, based on information gathered from senior managers and others.
} 


\subsubsection{Examples}

Success Criteria Success criteria define the measures used to characterize qualitative measures of the potential for success. The measures are used in Activity A4 to determine the current potential for success. When setting the success threshold, you are determining the desired potential for success. This example depicts success criteria using the aggregate driver score and success criteria presented in Example 9. The criteria from Example 9 are shown below in Example 14. (See section 3.3.4 for more information on aggregate driver score.)

\begin{tabular}{|llc|}
\hline Measure & \multicolumn{1}{c|}{ Description } & Range \\
Excellent & Conditions are extremely favorable for a successful outcome. & $8.5-10$ \\
High & Conditions are favorable for a successful outcome. & $6.5-8.4$ \\
Borderline & Conditions are mixed, making the outcome uncertain. & $3.5-6.4$ \\
Low & Conditions are not favorable for a successful outcome. & $1.5-3.4$ \\
Minimal & Conditions are extremely unfavorable for a successful outcome. & $0-1.4$ \\
\hline
\end{tabular}

Example 14: Success Criteria

SETting THE Success THRESHOLD
The success threshold reflects stakeholders' overall tolerance for risk. For this example, management and other stakeholders discussed their views about the desired potential for success. In many cases, managers focused on the tangible objectives of the project, for example:

- Customer satisfaction is a primary goal of the project. Managers were adamant about meeting the schedule with a highquality product that meets at least $95 \%$ of its stated functional requirements.

- The customer for this project is critical to the future success of the company, and therefore this project is critical.

The project being assessed is a straightforward development project that incorporates well understood technologies; it is low risk from a technical point of view. In addition, the project is more than half-way through its development life cycle. Based on the nature of the project, its goals, and the current life cycle phase, the success threshold is determined to be high. 
Success Profile for The example below depicts a success profile. The success threshold THE PROJect desired by stakeholders and managers was high, but the current potential for success is actually low. This sizeable gap is the success differential for the project.

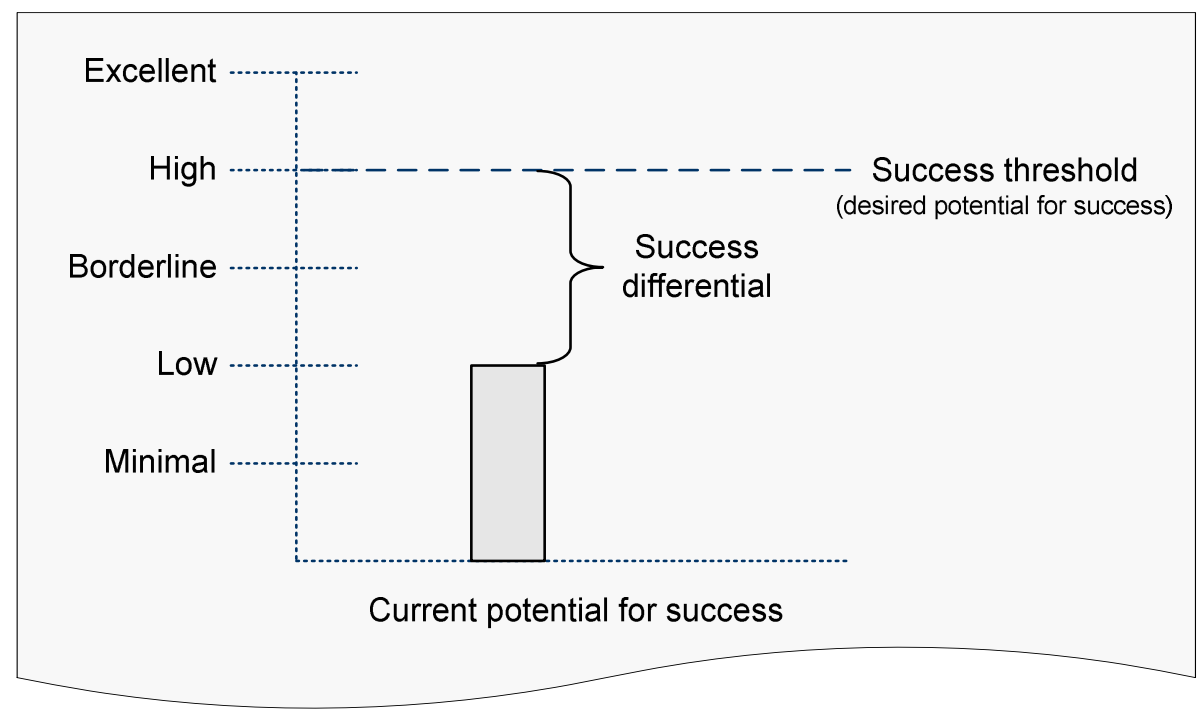

Example 15: Success Profile 


\subsubsection{DETERMINE NEXT STEPS (ACTIVITY A6)}

INTRODUCTION

OBJeCtive

\subsubsection{Dataflow}

This protocol activity identifies actions that will be implemented after the assessment to maintain or improve the current potential for success. The results of this activity serve as a bridge between the MDP assessment and any follow-on, detailed strategy development and planning activities. All actions, or next steps, identified during this protocol activity should be at an appropriate level of detail based on the goals of the assessment, depth and breadth of the data collected, analysis algorithm used, knowledge, skills, and abilities of the people conducting the assessment, and expectations of stakeholders. ${ }^{14}$

This activity answers the following question:

- What actions will help maintain or improve the current potential for success?

- Who is responsible for each action?

- By when must each action be completed?

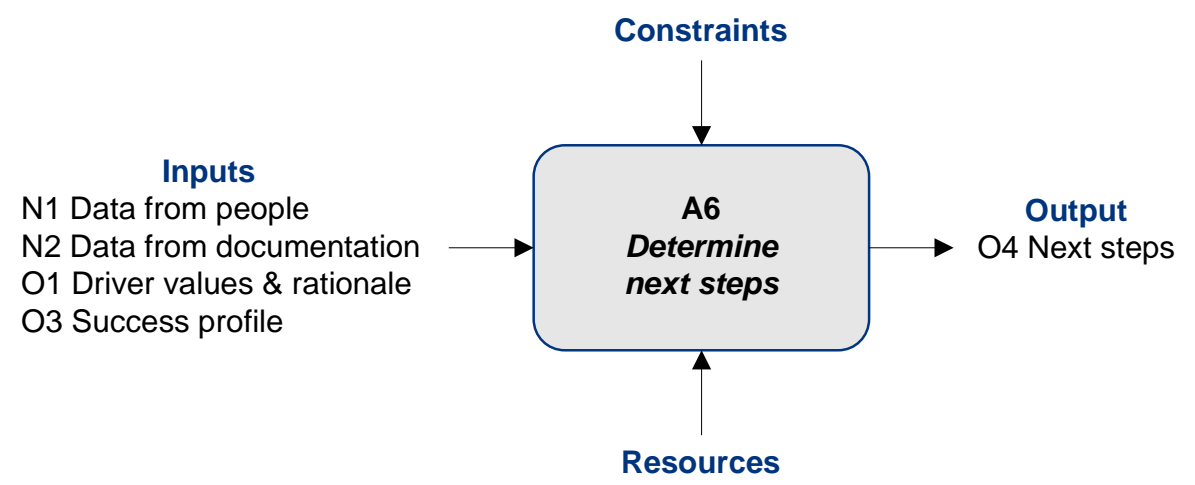

Figure 13: Inputs and Outputs for Activity A6

14 The results of this protocol activity can range from a simple set of recommendations or list of action items to a detailed plan that includes resource estimates, budget, and schedule. 


\begin{tabular}{|c|c|}
\hline Inputs and Output & Description \\
\hline N1 Data from people & $\begin{array}{l}\text { Usable data about a project or process based on individual and group perspec- } \\
\text { tives, information, and opinions about the project or process and its potential for } \\
\text { success }\end{array}$ \\
\hline $\begin{array}{l}\text { N2 Data from documenta- } \\
\text { tion }\end{array}$ & $\begin{array}{l}\text { Usable data about a project or process that is distilled from documentation, } \\
\text { such as policies, procedures, work products, and quality assurance data }\end{array}$ \\
\hline $\begin{array}{l}\text { O1 Driver values and ra- } \\
\text { tionale }\end{array}$ & $\begin{array}{l}\text { The current status of each driver, which includes } \\
\text { - the driver value } \\
\text { - rationale that explains why that value was selected }\end{array}$ \\
\hline O3 Success profile & $\begin{array}{l}\text { The current status of the project or process, including } \\
\text { - measure of the current potential for success } \\
\text { - measure of the desired potential for success, or success threshold } \\
\text { - analysis of the gap between the current potential for success and its suc- } \\
\text { cess threshold }\end{array}$ \\
\hline O4 Next steps & Actions that will be taken after the assessment is complete \\
\hline
\end{tabular}

\subsubsection{Techniques}

TECHNIQUES

\section{Action Planning}

\section{BRAINSTORMING}

Several types of techniques can be used when you are determining what approach to take after the assessment, including

- action planning

- brainstorming

- group decision making

Action planning is a basic technique for determining how to proceed after an MDP assessment is complete. When performing this technique, you (1) identify a candidate list of actions, or next steps, (often using brainstorming techniques) and (2) determine which of the candidate actions will be implemented after the assessment is complete. The results of action planning lay the groundwork for subsequent improvement activities.

Brainstorming is a basic technique for generating ideas. It can be used to identify a candidate list of actions for maintaining or improving the current potential for success. Many variants of brainstorming exist and can be used when performing this protocol activity. 
Group DECISION

MAKING

\subsubsection{Examples}

Next Steps
When selecting an appropriate set of next steps, you can use techniques to facilitate decision-making activities. For example, voting techniques, such as multi-voting, can help a group sort through differences and reach consensus.

For the example project, the current potential for success is low, while the desired potential for success is high. The results indicate that current conditions are not favorable for a successful outcome and that the gap between current and desired performance is large. The example below illustrates some of the actions selected by the project team. Detailed planning for each action was performed outside of the assessment process.

\begin{tabular}{|lll|}
\hline Action & Responsibility & Date \\
$\begin{array}{l}\text { Work with Center Director to resolve issues } \\
\text { between analysts and developers }\end{array}$ & Project Manager & July 3 \\
$\begin{array}{l}\text { Develop and implement a new strategy for com- } \\
\text { municating information with project team }\end{array}$ & Project Manager & July 3 \\
Begin a major replanning effort for the project & $\begin{array}{l}\text { Project Manager and } \\
\text { Technical Leads }\end{array}$ & July 12 \\
\hline
\end{tabular}

Example 16: Next Steps 


\subsection{COMPLETE POST-ASSESSMENT ACTIVITIES (PHASE 3)}

\section{ObJectives}

DATAFLOW
INTRODUCTION

Phase 3 conveys the results of the MDP assessment to key stakeholders and identifies actions that can help the efficiency and effectiveness of the MDP assessment. The objective when communicating assessment results to stakeholders is to present findings in a format that meets their needs and requirements. Different formats might be needed to communicate results to different types of stakeholders.

A postmortem is used to identify and document ways in which the MDP assessment can be improved. ${ }^{15}$ Updates and improvements to MDP assessment procedures, artifacts, tools, and training are made as appropriate.

This protocol phase answers the following questions:

- Who needs to know the results of the assessment? ${ }^{16}$

- What information does each stakeholder need?

- How should information be communicated to each stakeholder?

- What lessons were learned when preparing for the assessment?

- What lessons were learned when conducting the assessment?

- How do the assessment procedures, artifacts, tools, and training need to be updated or improved?

The following diagram highlights the dataflow for this protocol phase.

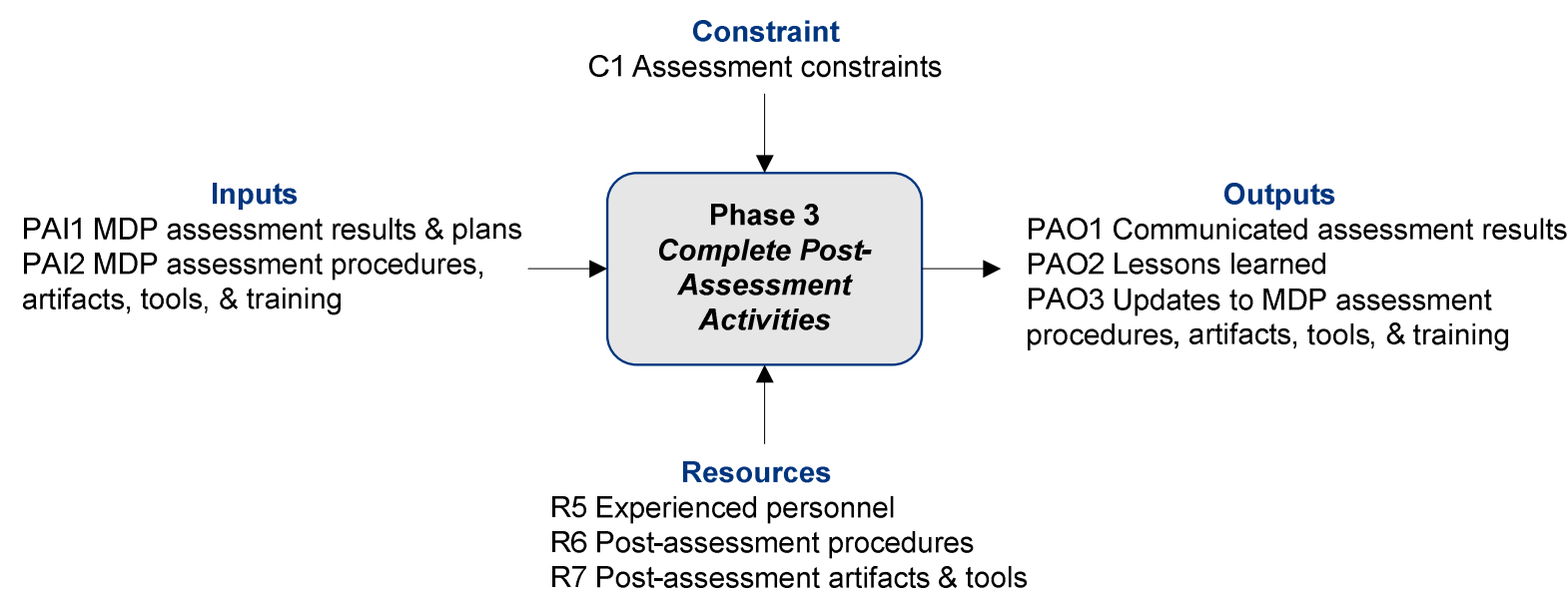

Figure 14: Dataflow for MDP Phase 3

\footnotetext{
15 Postmortems are usually conducted after a given assessment. However, they can also be held on a more periodic basis if multiple assessments are planned.

${ }^{16}$ Requirements for communicating assessment results are part of the assessment plan that is developed in Phase 1. These requirements are revisited in Phase 3 and are revised when appropriate (e.g., if new stakeholders are identified during the assessment).
} 

this protocol phase.

\begin{tabular}{|l|l|}
\hline Type & Description \\
\hline $\begin{array}{l}\text { PAl1 MDP assessment } \\
\text { results and plans }\end{array}$ & $\begin{array}{l}\text { All outputs produced by the MDP assessment, including findings and assess- } \\
\text { ment data, as well as plans, budget, and schedule for conducting the assess- } \\
\text { ment }\end{array}$ \\
\hline $\begin{array}{l}\text { PAI2 MDP assessment } \\
\text { procedures, artifacts, tools, } \\
\text { and training }\end{array}$ & $\begin{array}{l}\text { Supporting materials used to conduct an MDP assessment, including proce- } \\
\text { dures, worksheets, databases, and training artifacts }\end{array}$ \\
\hline
\end{tabular}

Constraint

The following constraint affects execution of the activities performed during this protocol phase.

\begin{tabular}{|l|l|}
\hline Type & Description \\
\hline C1 Assessment constraints & $\begin{array}{l}\text { Any circumstances, including logistics, personnel, schedule, and cost issues, } \\
\text { that could affect assessment activities }\end{array}$ \\
\hline
\end{tabular}

RESOURCES

The following resources support execution of the activities performed during this protocol phase.

\begin{tabular}{|l|l|}
\hline Type & Description \\
\hline R5 Experienced personnel & People who are experienced in all phases of an MDP assessment \\
\hline $\begin{array}{l}\text { R6 Post-assessment pro- } \\
\text { cedures }\end{array}$ & Documentation that describes how to conduct post-assessment activities \\
\hline $\begin{array}{l}\text { R7 Post-assessment arti- } \\
\text { facts and tools }\end{array}$ & $\begin{array}{l}\text { Templates, worksheets, standard presentations, automated tools, and data- } \\
\text { bases needed to conduct post-assessment activities }\end{array}$ \\
\hline
\end{tabular}



this protocol phase.

\begin{tabular}{|l|l|}
\hline Type & Description \\
\hline $\begin{array}{l}\text { PAO1 Communicated as- } \\
\text { sessment results }\end{array}$ & $\begin{array}{l}\text { Assessment results that have been conveyed to key stakeholders, including } \\
\text { - driver values }\end{array}$ \\
\hline $\begin{array}{l}\text { - success profile for the project or process } \\
\text { actions that need to be implemented to maintain or improve the current } \\
\text { potential for success }\end{array}$ \\
\hline PAO2 Lessons learned & $\begin{array}{l}\text { Knowledge gained by conducting an MDP assessment that can be used to } \\
\text { modify and improve future MDP assessments }\end{array}$ \\
\hline $\begin{array}{l}\text { PAO3 Updates to MDP } \\
\text { assessment procedures, } \\
\text { artifacts, tools, and training }\end{array}$ & $\begin{array}{l}\text { Any changes, based on lessons learned, to MDP assessment procedures, } \\
\text { artifacts, tools, and training intended to improve the efficiency and effectiveness } \\
\text { of future MDP assessments }\end{array}$ \\
\hline
\end{tabular}

Key Activities

The following table highlights the activities performed during this protocol phase. ${ }^{17}$

\begin{tabular}{|l|l|}
\hline Activity & Description \\
\hline Communicate results & Convey the results of the MDP assessment to key stakeholders \\
\hline $\begin{array}{l}\text { Conduct postmortem of the } \\
\text { MDP assessment }\end{array}$ & $\begin{array}{l}\text { Conduct one or more meetings to identify the strengths and weaknesses of the } \\
\text { MDP assessment and document modifications and improvement to the MDP } \\
\text { assessment process }\end{array}$ \\
\hline $\begin{array}{l}\text { Implement improvements to } \\
\text { the MDP assessment } \\
\text { process }\end{array}$ & $\begin{array}{l}\text { Make changes, based on lessons learned, to the MDP assessment process, } \\
\text { including updating procedures, artifacts, tools, and training as appropriate }\end{array}$ \\
\hline
\end{tabular}

17 Detailed descriptions of Phase 3 activities are not provided in this document. 


\section{Summary and Further Work}

Mission Success
RESEARCH AND
DEVELOPMENT

MDP IS A RISK-BASED APPROACH
In 2006, the Carnegie Mellon ${ }^{\circledR}$ SEI chartered the Mission Success in Complex Environments (MSCE) project to advance the riskmanagement state-of-the-practice. A key part of this project is the development of MOSAIC - a suite of risk-based methods for assessing and managing complex projects and processes.

An extensive and time-consuming analysis is normally required when conducting most commonly used risk assessments. An underlying goal of the SEI research and development activities related to MDP is to demonstrate that an assessment does not require a significant investment of time to be effective. In this way, people can more readily adopt risk-based approaches that help them weigh the alternatives confronting them and ultimately make better decisions.

MDP is the first MOSAIC assessment protocol to be published. Please refer to the MSCE web site for current information: http://www.sei.cmu.edu/msce/

MDP is a risk-based assessment for evaluating current conditions, determining a project's or process' current potential for success, and actions that will help maintain or improve the current potential for success over time. It can be applied to projects and processes across the life cycle and throughout the supply chain and is designed to help people analyze tradeoffs and make better decisions in situations that have a high degree of uncertainty. When used properly, an MDP assessment provides a time- and resource-efficient way to identify major issues that can affect the potential for success.

A small set of drivers is used to gauge the current conditions affecting a project or process. Then, a simple algorithm is applied to the set of drivers to determine the degree of momentum toward the desired outcome, which allows for actionable assessment results without having extensive expertise in conducting assessments. However, an MDP assessment only provides a "ballpark" measure of the potential for success. It can be viewed as a first-pass screening of a project or process to diagnose any unusual circumstances that might affect its potential for success. More detailed, follow-on evaluations might be required when the potential for success is judged to be unacceptable.

Carnegie Mellon is registered in the U.S. Patent and Trademark Office by Carnegie Mellon University. 


\section{MDP PILOTS}

MOSAIC

MANAGEMENT

APPROACH
MDP was designed for use in many different domains and types of problems. To date, MDP has been piloted in the following domains:

- cyber-security incident response

- project portfolio management

- software development

Early piloting of MDP has demonstrated its flexibility by showing how it can be applied in a variety of domains and environments, across the life cycle, and throughout the supply chain.

MOSAIC requires establishing and maintaining a reasonable degree of confidence that objectives will be achieved successfully. Figure 15 depicts the key activities performed when using MOSAIC to manage a project or process. Notice that an assessment is a key activity of this approach. However, assessing the current potential for success (using MDP for example) is just one part of the broader management approach. Additional follow-on activities are needed to help ensure that the desired outcome will be achieved.

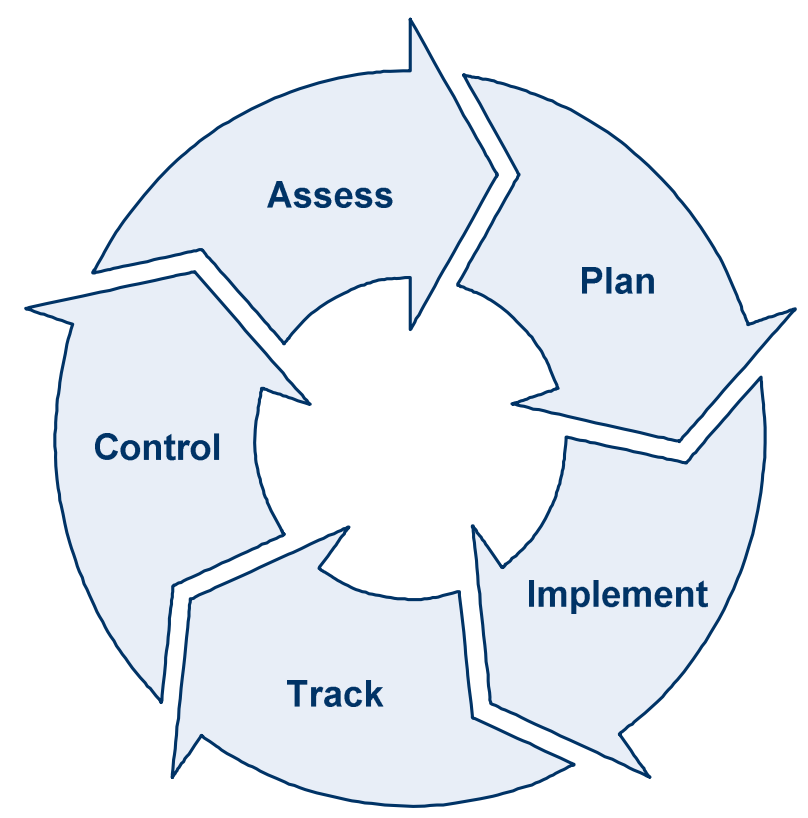

Figure 15: MOSAIC Management Paradigm 
MOSAIC

MANAGEMENT

ACTIVITIES

FUTURE MDP

DEVELOPMENT

MSCE RESEARCH DIRECTIONS AND GOAL
As illustrated in Figure 15, MOSAIC requires completing the following key activities:

- Assess-determine the current potential for success in relation to its success threshold

- Plan-develop a detailed action plan for maintaining or improving the potential for success over time

- Implement-execute plans as defined

- Track-monitor the status of plan milestones and measures of plan effectiveness

- Control-make adjustments to plans when appropriate

MDP enables you to assess the current potential for success. In addition, it also kicks off the planning activity by identify how to proceed after the assessment is complete. Additional follow-on planning is normally required to develop a formal improvement plan.

MDP is an important piece of research because it provides a foundation for future research and development activities related to MOSAIC. We intend to continue piloting MDP in different venues. We also intend to publish guidebooks focusing on how to conduct an MDP assessment, and, when appropriate, we will also develop domain-specific methods consistent with MDP.

We intend to continue developing the MOSAIC suite of assessment and management methods. The early focus of MOSAIC research has been on assessing the potential for success. Future research will focus on developing approaches for managing the potential for success over time.

Overall, the main goal of our research is to transform risk management from a hazard-driven discipline to a success- and opportunity-driven discipline. Our work with MDP is the first step toward achieving that goal. 


\section{Appendix A: Risk Management Concepts}

MULTIPLE CONTEXTS
OF RISK MANAGEMENT

\section{THREE}

Characteristics of

RISK

THREe Conditions OF RISK
The term risk is used universally, but different audiences often attach different meanings to it [Kloman 90]. In fact, the details about risk and how it supports decision making depend upon the context in which it is applied [Charette 90]. For example, safety professionals view risk management in terms of reducing the number of accidents and injuries. A hospital administrator views risk as part of the organization's quality assurance program, while the insurance industry relies on risk management techniques when setting insurance rates. Each industry thus uses a definition that is uniquely tailored to its context. No universally accepted definition of risk exists.

Whereas specific definitions of risk might vary, a few characteristics are common to all definitions. For risk to exist in any circumstance, the following three conditions must be satisfied [Charette 1990]:

1. The potential for loss must exist.

2. Uncertainty with respect to the eventual outcome must be present. $^{18}$

3. Some choice or decision is required to deal with the uncertainty and potential for loss.

The three characteristics can be used to forge a very basic definition of the word risk. Most definitions focus on the first two conditions-loss and uncertainty - because they are the two measurable aspects of risk. Thus, the essence of risk, no matter what the domain, can be succinctly captured by the following definition: Risk is the possibility of suffering loss [Dorofee 1996].

\footnotetext{
18 Some researchers separate the concepts of certainty (the absence of doubt), risk (where the probabilities of alternative outcomes are known), and uncertainty (where the probabilities of possible outcomes are unknown). However, because uncertainty is a fundamental attribute of risk, we do not differentiate between decision making under risk and decision making under uncertainty in this technical report.
} 
SPECULATIVE AND

HAZARD RISK

Speculative Risk

EXAMPLE: GAMBLING
Sometimes a situation presents an opportunity for gain as well as the potential for loss. In other instances, only the potential for loss exists. Because of this difference, risk can thus be further subdivided into two types: speculative risk and hazard risk [Young 2001]. Figure 16 graphically illustrates the difference between speculative and hazard risk.

With speculative risk you might realize a gain, which can improve your current situation relative to the status quo. At the same time, you might experience a loss, which can make your situation worse than it is at present. In contrast, hazard risk provides no opportunity to improve upon the current situation; it only brings the potential for loss.

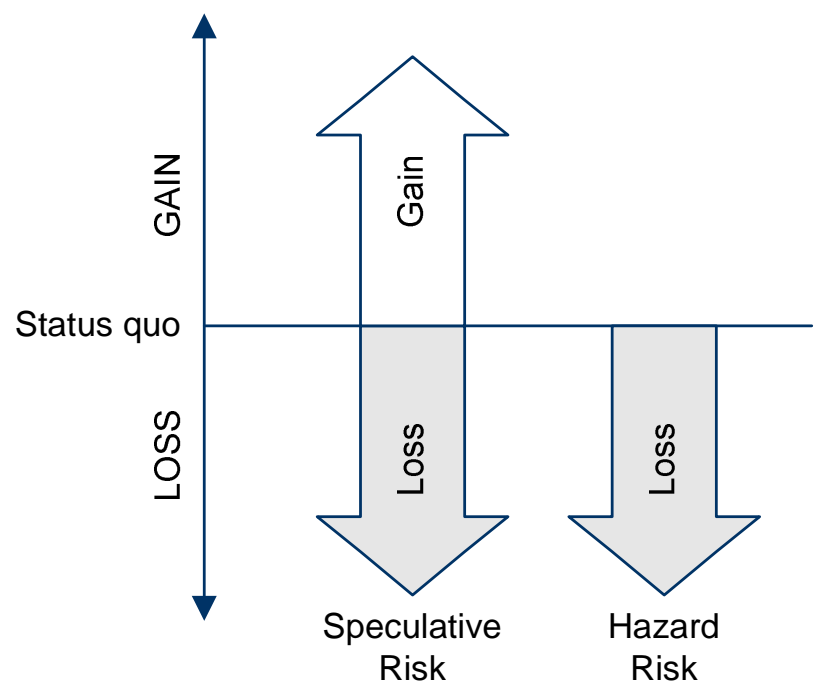

Figure 16: Speculative and Hazard Risks

Gambling is an example of taking a speculative risk. When you place a bet, you must balance the potential for gain against the potential for loss. You weigh the possibility of gaining additional money against the prospect of losing the funds you wagered. When you gamble, your objective is to increase your wealth in relation to the status quo, and you are willing to put your finances at risk for the opportunity to make money. 
SPECULATIVe Risk

EXAMPLE: BUSINESS

RISK

HAZARD RISK

EXAMPLE: SECURITY

Speculative Risk

EXAMPLE: SECURITY

IMPORTANCE OF

CONTEXT

60 | CMU/SEI-2008-TR-005
Business risk is another example of speculative risk. When managers invest organizational assets, they must balance the risk of investing organizational capital against the potential return on that investment. From an economic perspective, as an organization's risk increases, its potential return on investment had better increase correspondingly. Management should never take on additional risk unless the potential for increased profits also exists. The balance of risk and opportunity drives all business decisions, which makes business risk speculative.

Consider how security can be viewed as a hazard risk. Imagine that you are concerned about protecting valuables that are stored in your home. Your main objective in this example is to ensure that none of the valuables in your residence is removed without your knowledge and permission. After evaluating how well your valuables are protected, you might decide to install a security system in your residence to make it more difficult for a thief to break in and steal your valuables. Notice that the objective in this example, by definition, restricts the focus of risk on the potential for loss. In the most favorable of circumstances, you only keep what you already possess. There is no potential for gain.

Now consider the same example when viewed from another perspective. In this instance, you would like to gain peace of mind by preventing unsavory characters from gaining entrance to your house. Your objective to feel more secure defines the context in which you view risk. After analyzing the situation, you might decide to install a security system in your residence to make it more difficult for someone to break in. You might reason that the added protection will make you feel more secure and help you gain the peace of mind you seek. In this example, you are willing to invest money in a security system to provide yourself an opportunity feel more secure. The security risk in this example is speculative because it balances your tolerance for risk (i.e., the amount of money you are willing to invest in a security system) with your desire to realize an opportunity (i.e., gaining peace of mind).

The two security examples illustrate how the same situation can be viewed as a hazard risk in one context and a speculative risk in another. A risk therefore is classified as speculative or hazard based on the context in which it is viewed. The notion of explicitly establishing the context in which you analyze and manage risk is vitally important to ensure that you make appropriate choices about how you manage your risk. 
Five Common

ELEMENTS

\section{CONTEXT}

EXAMPLE: Project MANAGEMENT CONTEXT
All forms of risk, whether they are classified as speculative or hazard risk, comprise common elements. This notion is illustrated in Figure 17, which highlights the following five common elements of risk: (1) context, (2) execution, (3) conditions, (4) potential events, and (5) range of potential outcomes.

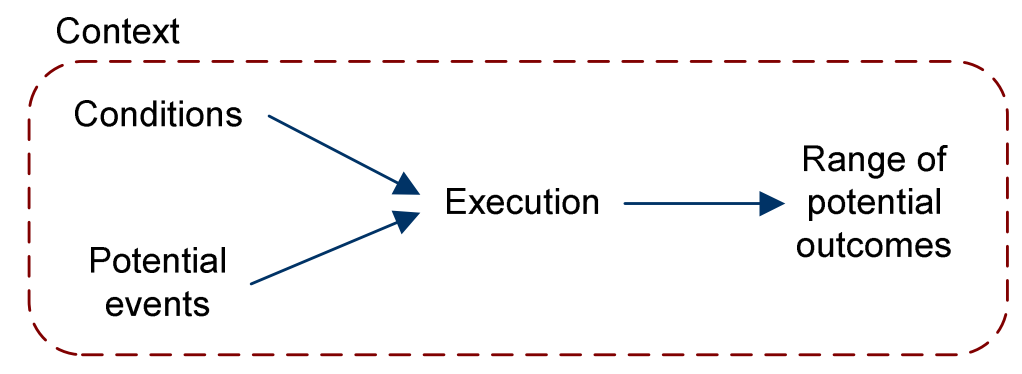

Figure 17: Common Elements of Risk

Context provides the background, situation, or environment in which a project or process is executed. It generally includes the key objectives being pursued as well as stakeholders' expectations for those objectives. ${ }^{19}$ It defines the picture of success for a given set of objectives and provides the lens through which all potential outcomes are viewed and interpreted. Defining the context is thus an essential first step when managing any type of risk.

Assume that you are a project manager who is overseeing the development of a software-intensive system. Suppose that these are the most important objectives to you: product, cost, and schedule. These objectives indicate that you are focused on developing a fully functional system on time and within budget. Now, suppose that stakeholders (such as senior managers in your organization) are very concerned about cost overruns and have made it clear that the project cannot exceed its budget. As a result, the cost objective becomes your primary objective among the three, and your tolerance for cost risk is low. Your decisions will be driven by your low tolerance for cost overruns. When you are forced to make tradeoffs, unacceptable outcomes related to cost will have a greater influence than those related to product and schedule objectives.

19 Stakeholders include all interested parties, customers, and suppliers, both internal and external to an organization. 
FOUNDATION OF RISK MANAGEMENT

EXECUTION

Conditions

EXAMPLE: CONDITIONS THAT DIRECTLY INFLUENCE AN OUTCOME

EXPOSING CONDITIONS

Potential Events
The context in the above example has been defined by three project objectives and the expectations related to those objectives. Without setting an appropriate context, you cannot definitively determine how to gauge the potential for success or how to assess any given outcome. Context thus forms the underlying foundation when managing risk.

Execution describes what must be done to achieve a set of objectives. With respect to a project or process, execution refers to the activities that are performed when working toward the objectives.

Conditions define the circumstances that directly or indirectly influence execution and drive an outcome toward success or failure. As a project or process is executed, these conditions affect the eventual outcome. In some instances, conditions directly influence the outcome; while in others, they indirectly affect the outcome by creating exposure to negative or positive events.

Consider an example where a team is developing a software-intensive system. Suppose that the following condition is present: team members have not previously worked with the design language being used on the project. This could cause them to make mistakes or take more time when working on tasks, driving product, cost, and schedule objectives toward one or more undesired outcomes. Here, the condition has a direct influence on the eventual outcome.

Conditions that expose a project or process to the effects of events that might (or might not) occur are called exposing conditions. During normal day-to-day operations, these conditions lie dormant and do not produce any visible effect on results. However, certain events in combination with exposing conditions can influence the expected outcome. $^{20}$

A potential event is an unpredictable occurrence that combines with one or more exposing conditions to affect performance and thus drive the outcome toward success or failure.

${ }^{20}$ Events can have a positive or negative effect on the outcome depending on the specific nature of the event. For example, an increase in funding would likely be perceived as a positive event that might put a project in better position for success. On the other hand, a decrease in funding would likely be perceived as a negative event that might adversely affect a project's outcome. 
EXAMPLE: PotentIAL EVENTS AND EXPOSING CONDITIONS

RANGE OF POTENTIAL OUTCOMES

TRADITIONAL RISK

MANAGEMENT

APPROACHES
A computer virus is a program that is designed to exploit certain exposing conditions (called vulnerabilities) and infect computers causing them to act erratically. People with malicious intent design these programs with the ultimate goal of wreaking havoc throughout the business community, such as degrading the performance of computers and networks or rendering them unavailable for use. If a work process is highly dependent on the availability of computers and networks that become infected, production can be temporarily halted, which can lead to an undesirable outcome. ${ }^{21}$ Notice that the condition, the system's vulnerability, poses no threat to production during normal operations. It takes an unpredictable event, the proliferation of a computer virus, for damage to occur. This particular condition only affects the process' outcome when a relevant event occurs.

The range of potential outcomes defines the set of possible results that can be achieved when executing a project or process. Some outcomes will be considered to be acceptable, while others will be viewed as unacceptable.

Most risk-management approaches, when applied to projects and processes, have traditionally assumed a hazard view of risk. From the hazard perspective, a risk is viewed as a potential obstacle that can interfere with positive momentum or progress, and a threat is defined as a condition or event that could lead to a risk [Alberts 2005]. When viewed from this perspective, traditional risk management focuses on reducing or eliminating obstacles that might interfere with momentum or progress. In addition, traditional risk management approaches have not considered multiple organizations; they focus within an organization and locally optimize risk for that organization.

Traditional risk-management approaches, when applied to projects and processes, focus on individual conditions or potential events. A risk analysis is then used to estimate the potential consequence triggered by each condition or event.

${ }^{21}$ Undesirable from the business' perspective, that is. From the virus developer's perspective, this would be considered a successful outcome. 


\section{RISK STATEMENT}

BASIC RISK MANAGEMENT ACTIVITIES
A risk is normally represented using a linear cause-and-effect pair that conveys two key pieces of information: (1) the threat (i.e., condition or potential event) that is causing concern and (2) the potential consequences of that threat [Gluch 1994]. Each cause-and-effect pair, or risk statement, can be viewed as a scenario that documents the potential loss triggered by a given condition or event. Figure 18 illustrates the notion of multiple risks that can affect a project or process. The list of risks becomes the focal point of risk management activities in traditional approaches.

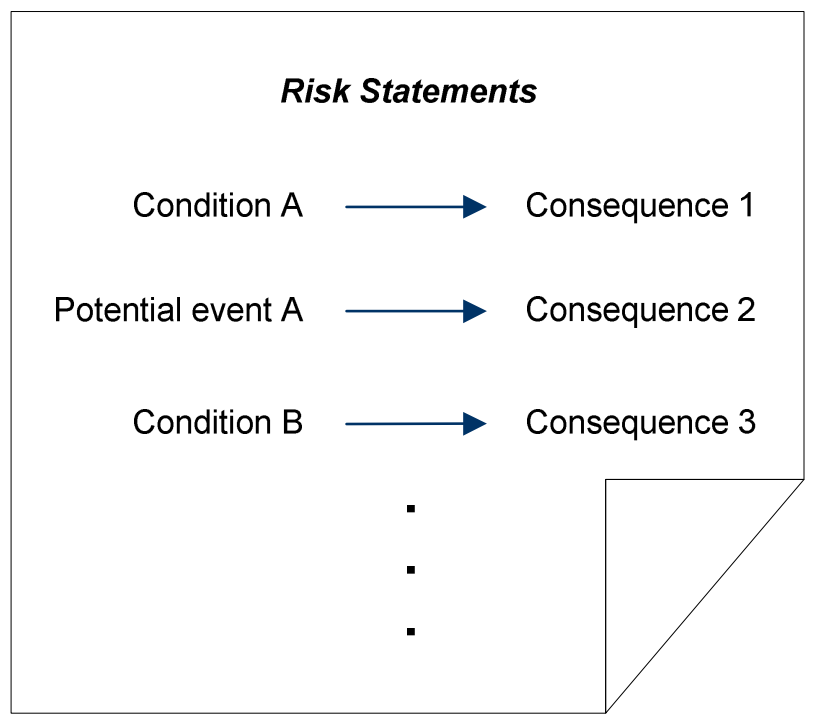

Figure 18: Cause and Effect Risk Statement

Traditional risk-management approaches generally require people to conduct the following types of activities:

- identify risks that can lead to loss

- prioritize the list of risk statements based on objectives, requirements, and constraints

- develop mitigation plans for the highest priority risks

- implement the mitigation plans as defined

- track the status of mitigation plan milestones and measures of effectiveness

- make adjustments to mitigation plans when appropriate 


\section{Appendix B: Protocol Structure and Nomenclature}

INFORMATION

FOR ALL PHASES

INFORMATION

FOR PHASE 2

ACTIVITIES
Table 1 describes the information provided in this report for all phases of the Mission Diagnostic Protocol.

\begin{tabular}{|l|l|}
\hline \multicolumn{1}{|c|}{ Information Type } & \multicolumn{1}{c|}{ Description } \\
\hline Introduction & A brief introduction describing the key aspects of the phase \\
\hline Objectives & Key objectives for the phase worded as questions \\
\hline Dataflow & $\begin{array}{l}\text { A high-level dataflow diagram for the protocol phase } \\
\text { Note: For Phase } 2 \text { of an assessment protocol, a detailed } \\
\text { dataflow of all activities is also provided. }\end{array}$ \\
\hline Inputs & Data that are required by a protocol phase \\
\hline Constraints & The limitations imposed on a protocol phase or activity \\
\hline Resources & $\begin{array}{l}\text { Procedures, plans, artifacts, tools, people, and other re- } \\
\text { sources that support execution of a protocol phase }\end{array}$ \\
\hline Outputs & Data that are produced by a protocol phase \\
\hline Key activities & $\begin{array}{l}\text { A brief description of the activities performed during the } \\
\text { phase }\end{array}$ \\
\hline
\end{tabular}

Table 1: Information Types for all Assessment Phases

Table 2 describes the information provided for each Phase 2 activity. The same constraints and resources apply to all Phase 2 activities. Therefore, descriptions of constraints and resources are presented in Phase 2 and are not repeated for each individual Phase 2 activity.

\begin{tabular}{|l|l|}
\hline \multicolumn{1}{|c|}{ Information Type } & \multicolumn{1}{c|}{ Description } \\
\hline Introduction & $\begin{array}{l}\text { A brief introduction describing the key aspects of the proto- } \\
\text { col activity }\end{array}$ \\
\hline Objectives & Key objectives for the protocol activity worded as questions \\
\hline Dataflow & A high-level dataflow diagram for the protocol activity \\
\hline Inputs & Data that are required by a protocol activity \\
\hline Outputs & Data that are produced by a protocol activity \\
\hline Techniques & $\begin{array}{l}\text { A brief description of the types of techniques that can be } \\
\text { used to conduct the protocol activity }\end{array}$ \\
\hline
\end{tabular}

Table 2: Information Types for each Phase 2 Activity 
DATAFLOW STRUCTURE

DATAFLOW IDENTIFIERS
Figure 19 depicts the data types included in a protocol dataflow. The same data types are used when documenting the dataflow for a protocol phase or an activity.

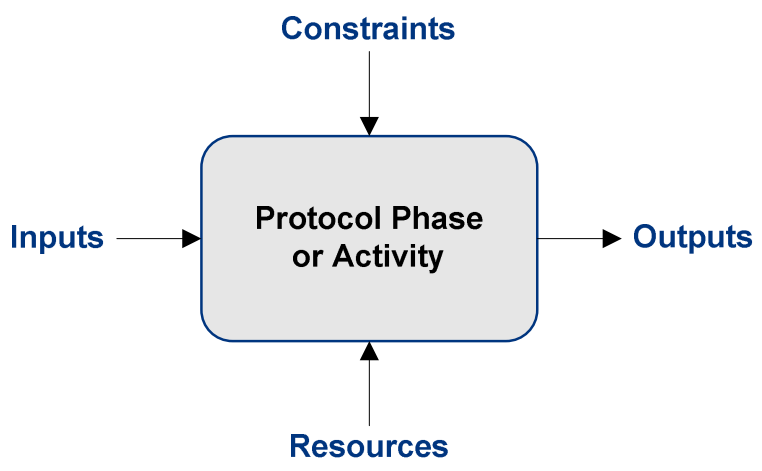

Figure 19: Protocol Data Types

Each input, output, constraint, and resource listed in a dataflow is represented by an identifier, which includes a prefix and a number. The prefix is based on the type of data and the number represents a data element. Table 3 illustrates the prefixes used in each assessment phase.

\begin{tabular}{|c|c|}
\hline Assessment Phase & Prefixes \\
\hline \multirow[t]{4}{*}{ Phase 1} & $P R I$ is an input. \\
\hline & $P R O$ is an output. \\
\hline & $C$ is a constraint. \\
\hline & $R$ is a resource. \\
\hline \multirow[t]{5}{*}{ Phase 2} & $I$ is an input. \\
\hline & $\begin{array}{l}N \text { is an output generated by one of Phase 2's activities that } \\
\text { is not a final output of the phase. (It is called an interim } \\
\text { output.) }\end{array}$ \\
\hline & $O$ is a final output of Phase 2. \\
\hline & $C$ is a constraint. \\
\hline & $\begin{array}{l}P R O \text { is an output of Phase } 1 \text { that either acts as a constraint } \\
\text { or is used as a resource in Phase } 2 \text {. }\end{array}$ \\
\hline \multirow[t]{4}{*}{ Phase 3} & $P A /$ is an input. \\
\hline & $P A O$ is an output. \\
\hline & $C$ is a constraint. \\
\hline & $R$ is a resource. \\
\hline
\end{tabular}

Table 3: Dataflow Prefixes 
EXAMPLE DATAFLOW IDENTIFIERS
Table 4 illustrates the convention for documenting dataflow identifiers in MDP.

\begin{tabular}{|l|l|}
\hline \multicolumn{1}{|c|}{ Dataflow Identifier } & \multicolumn{1}{c|}{ Description } \\
\hline $\begin{array}{l}\text { PRO2 Assessment } \\
\text { scope }\end{array}$ & $\begin{array}{l}\text { The second output of Phase 1. It also acts as a constraint } \\
\text { for all Phase 2 activities. }\end{array}$ \\
\hline $\begin{array}{l}\text { PRO6 MDP assess- } \\
\text { ment procedures }\end{array}$ & $\begin{array}{l}\text { The sixth output of Phase 1. It also acts as a resource for all } \\
\text { Phase 2 activities. }\end{array}$ \\
\hline $\begin{array}{l}\text { C1 Assessment con- } \\
\text { straints }\end{array}$ & $\begin{array}{l}\text { The first constraint for the protocol. It can apply to any } \\
\text { phase or activity. }\end{array}$ \\
\hline $\begin{array}{l}\text { I2 Mission documenta- } \\
\text { tion }\end{array}$ & $\begin{array}{l}\text { The second input of Phase 2. It is also an input to one of } \\
\text { Phase 2's activities. }\end{array}$ \\
\hline $\begin{array}{l}\text { N2 Data from docu- } \\
\text { mentation }\end{array}$ & $\begin{array}{l}\text { The second interim output of Phase 2. It is also an input to } \\
\text { several of Phase 2's activities. }\end{array}$ \\
\hline $\begin{array}{l}\text { PAO1 Communicated } \\
\text { assessment results }\end{array}$ & \begin{tabular}{l} 
The first output of Phase 3. \\
\hline
\end{tabular}
\end{tabular}

Table 4: Dataflow Identifier Examples 


\section{References}

\section{[Alberts 2007]}

Alberts, Christopher, Dorofee, Audrey, \& Marino, Lisa. Executive Overview of SEI MOSAIC:

Managing for Success using a Risk-Based Approach (CMU/SEI-2007-TN-008). Pittsburgh, PA:

Software Engineering Institute, Carnegie Mellon University, 2007.

http://www.sei.cmu.edu/publications/documents/07.reports/07tn008.html

\section{[Alberts 2005]}

Alberts, Christopher \& Dorofee, Audrey. Mission Assurance Analysis Protocol (MAAP): Assessing Risk in Complex Environments (CMU/SEI-2005-TN-032, ADA441906). Pittsburgh, PA:

Software Engineering Institute, Carnegie Mellon University, 2005.

http://www.sei.cmu.edu/publications/documents/05.reports/05tn032.html

\section{[Charette 1990]}

Charette, Robert N. Application Strategies for Risk Analysis. New York, NY: McGraw-Hill Book Company, 1990.

\section{[Dorofee 1996]}

Dorofee, A., Walker, J., Alberts, C., Higuera, R., Murphy, R., \& Williams, R. Continuous Risk Management Guidebook. Pittsburgh, PA, Software Engineering Institute, Carnegie Mellon University, 1996.

http://www.sei.cmu.edu/publications/books/other-books/crm.guidebk.html

\section{[Gluch 1994]}

Gluch, D. A Construct for Describing Software Development Risks (CMU/SEI-94-TR-014, ADA284922). Pittsburgh, PA: Software Engineering Institute, Carnegie Mellon University, 1994. http://www.sei.cmu.edu/publications/documents/94.reports/94.tr.014.html

\section{[Kloman 1990]}

Kloman, H. F. "Risk Management Agonists.” Risk Analysis 10, 2 (June 1990): 201-205.

\section{[Young 2001]}

Young, Peter C. \& Tippins, Steven C. Managing Business Risk. New York, NY: American Management Association, 2001. 


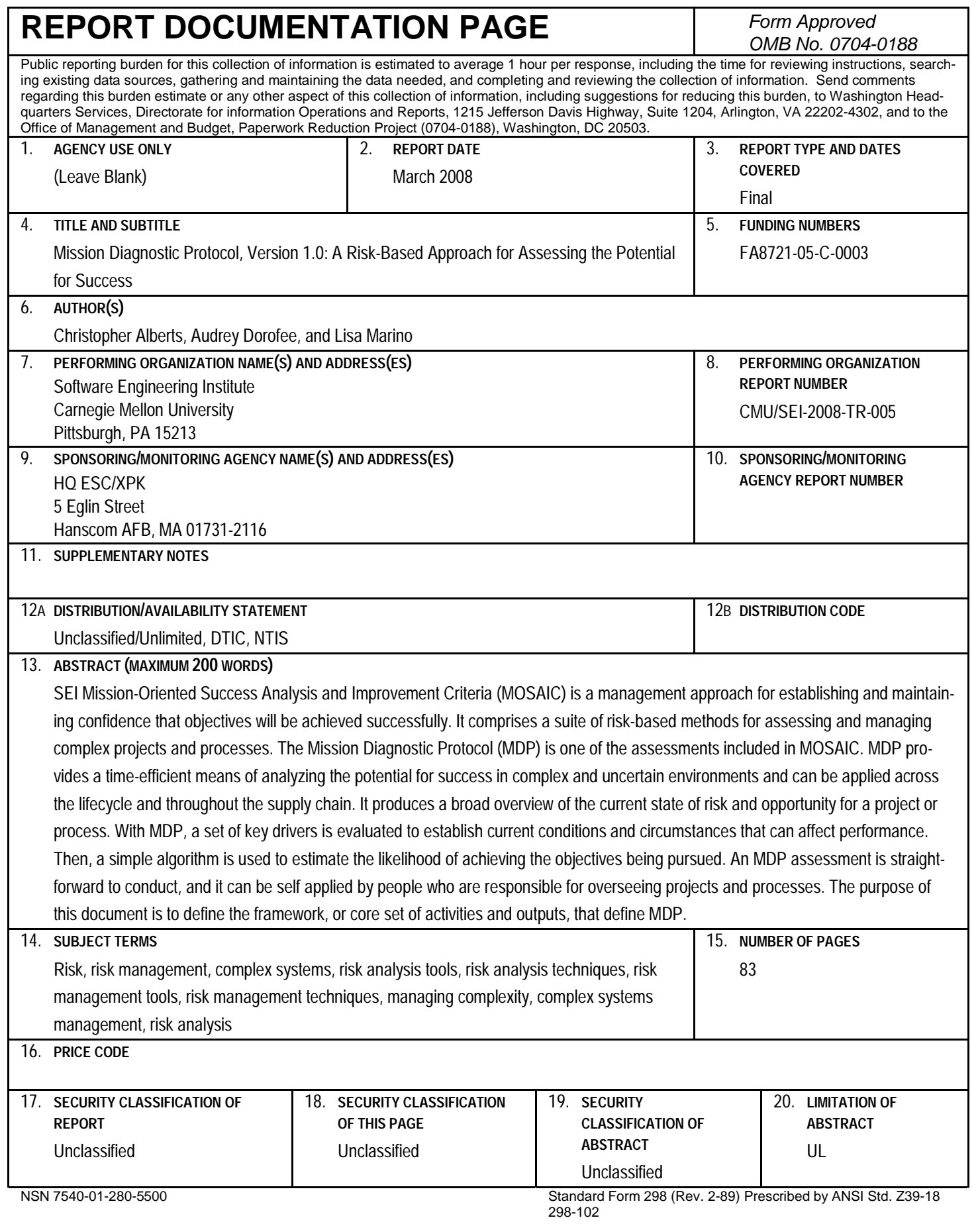

